\title{
The Next Epoch Seed Library's Lawn Lab: A Public Experiment in Collaboration with Seeds, Time, and Weeds
}

\author{
Ellie Irons ${ }^{a}$ \\ Keywords: ecosocial art, urban ecology, rewilding, socially engaged art, multispecies, climate justice \\ https://doi.org/10.1525/001c.13470
}

\begin{abstract}
This article and the accompanying media essay describe my experience developing and implementing the collaborative, interdisciplinary art project The Lawn (Re)Disturbance Laboratory (Lawn Lab). Combining urban ecology, socially engaged art, and multispecies pedagogy, Lawn Lab takes what I define as a critical, ecosocial approach to environmental art. As a public, socially engaged project, it provides a framework for establishing rewilding interventions in institutional and residential lawns from seeds lying dormant in the soil. Focusing on Lawn Lab's inaugural season, I describe how the project grew out of the Next Epoch Seed Library (NESL), an artist-run organization I cofounded in 2014 to collect, store, and share the seeds of spontaneous urban plants (a.k.a. weeds). After contextualizing NESL and Lawn Lab as part of a larger community of practitioners who work with vegetal attunement and entanglement in urban and disturbed landscapes, I describe the project's implementation and progress over its first season. I close by connecting my experience implementing the first season of Lawn Lab to Georgina Born and Andrew Barry's concept of the public experiment, part of their framework for analyzing how knowledge is produced through public-facing, interdisciplinary projects at the intersection of art and science. I use this framework to explore how Lawn Lab provides a forum for imagining and enacting new possibilities around landscape maintenance and care, urban biodiversity, and public health, offering collaboration with weedy plants as one means of working toward ecological justice in the face of a protracted environmental crisis.
\end{abstract}

The turf spreads out for hundreds of feet in all directions. It rolls thickly over the smooth contours of the slope where I am kneeling, spade in hand. I brush my palm over rough tips of freshly trimmed grass stems and leaves-Kentucky bluegrass, probably - and wonder how recently it was treated with herbicide. The lawn is nearly an uninterrupted monoculture. A few wisps of crabgrass stand out here and there, a slightly cooler shade of green. The turf is still and silent, cut so close to the soil that the light breeze of this April afternoon does nothing to move it.

When we chose this site back in February, a university groundskeeper told me the undulations on this slope are the foundations of structures that were built centuries ago, then demolished when the university bought the property. Now, pondering the other histories I know are occluded here, I take a deep breath and, with a concerted push, shove the spade through the grass and into the

\footnotetext{
a Ellie Irons is an artist and educator based in Brooklyn and Troy, New York. She works in a variety of media, from video to workshops to rewilding experiments, to reveal how human and nonhuman lives intertwine with other earth systems. Her recent work focuses on plants, people, and urban ecosystems in the so-called Anthropocene. She is a cofounder of the Next Epoch Seed Library and the Environmental Performance Agency, and received her BA from Scripps College in Los Angeles and her MFA from Hunter College, CUNY. She is currently pursuing a Ph.D. in electronic arts at Rensselaer Polytechnic Institute, where she is researching the intersection of socially engaged art, community science, and urban ecology as a means for envisioning and enacting multispecies solidarity in the face of climate chaos.
} 


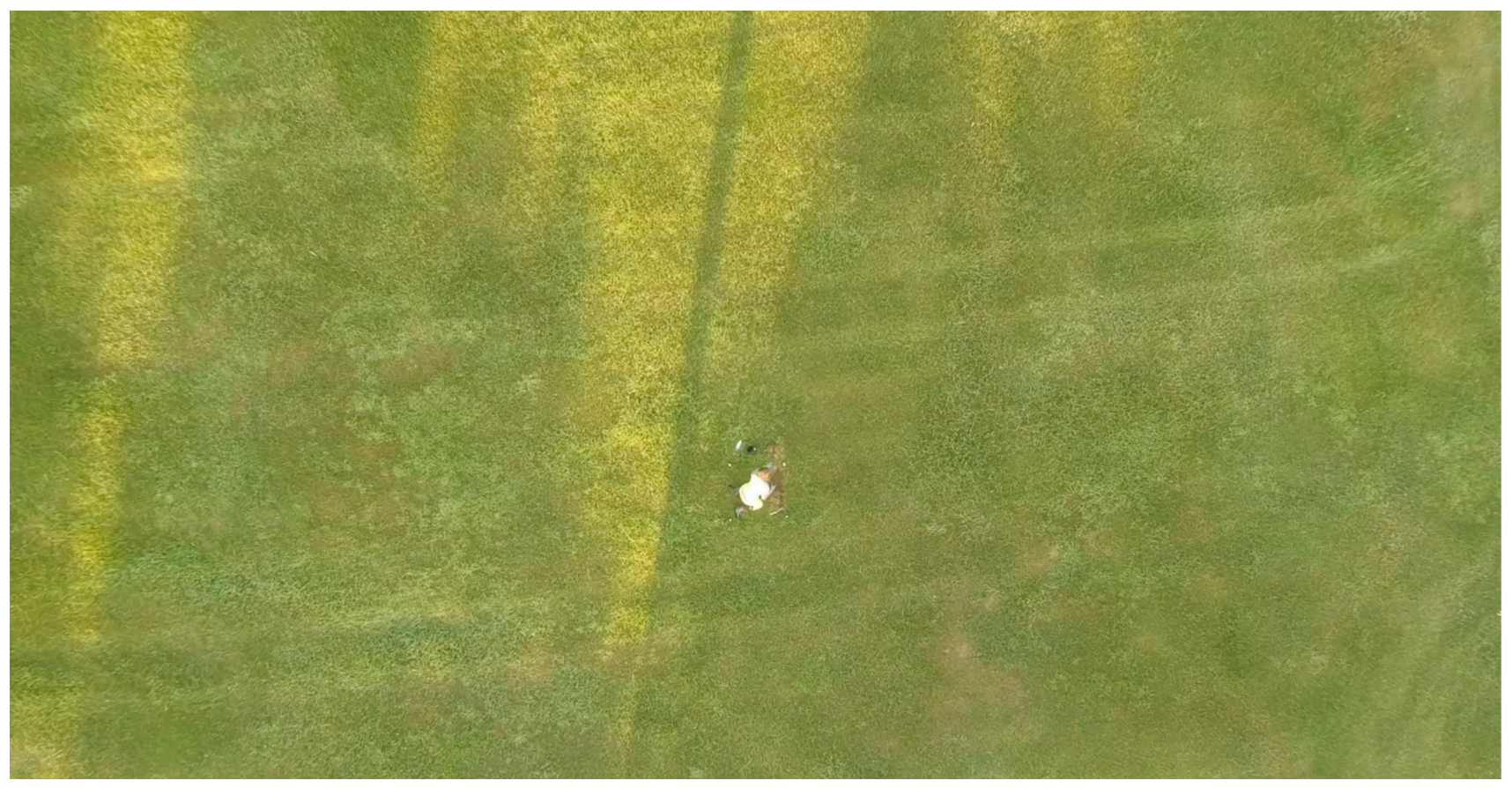

Figure 1: A brief video essay documenting the establishment of a Lawn Lab plot and its growth across a season.

Video available at: https://vimeo.com/432698545/e1ec5ff1d2

soil. I pause to consider the life I'm disrupting, then wrench the spade upward. Roots stretch and rip, chunks of soil rain down, and moments later the moist scent of earth meets my nostrils.

With this gesture, the first plot of the first season of the Lawn $(\mathrm{Re})$ Disturbance Laboratory is underway. Over the next two hours I labor, using a spade and a hand rake, to remove more than sixty pounds of turf from a one-square-meter patch of lawn, creating a square of open earth in a sea of green. When I stand over the newly established plot, the soil looks vulnerable and exposed, a raw, abstract form imposed on a rich, verdant carpet. But I know this impression is actually an inversion. The lawn is verdant in appearance only. Its richness is in reality a wound, and my destructive act activates the ingredients needed to repair it. All we need to do is wait.

\section{The Next Epoch Seed Library: Learning with Weeds}

The vignette above describes a key moment in the founding season of the Lawn (Re)Disturbance Laboratory (Lawn Lab). This "public experiment in collaboration with seeds, time, and weeds" is a project of the Next Epoch Seed Library (NESL). Based in the northeastern United States, NESL is an artistrun organization I cofounded in 2015 with sculptor Anne Percoco. Drawing on Anne's background working with repurposed and waste materials and my background in environmental science and art education, we launched NESL with a focus on collecting, storing, and sharing the seeds of spontaneous urban plants (a.k.a. weeds) in the greater New York City area. 


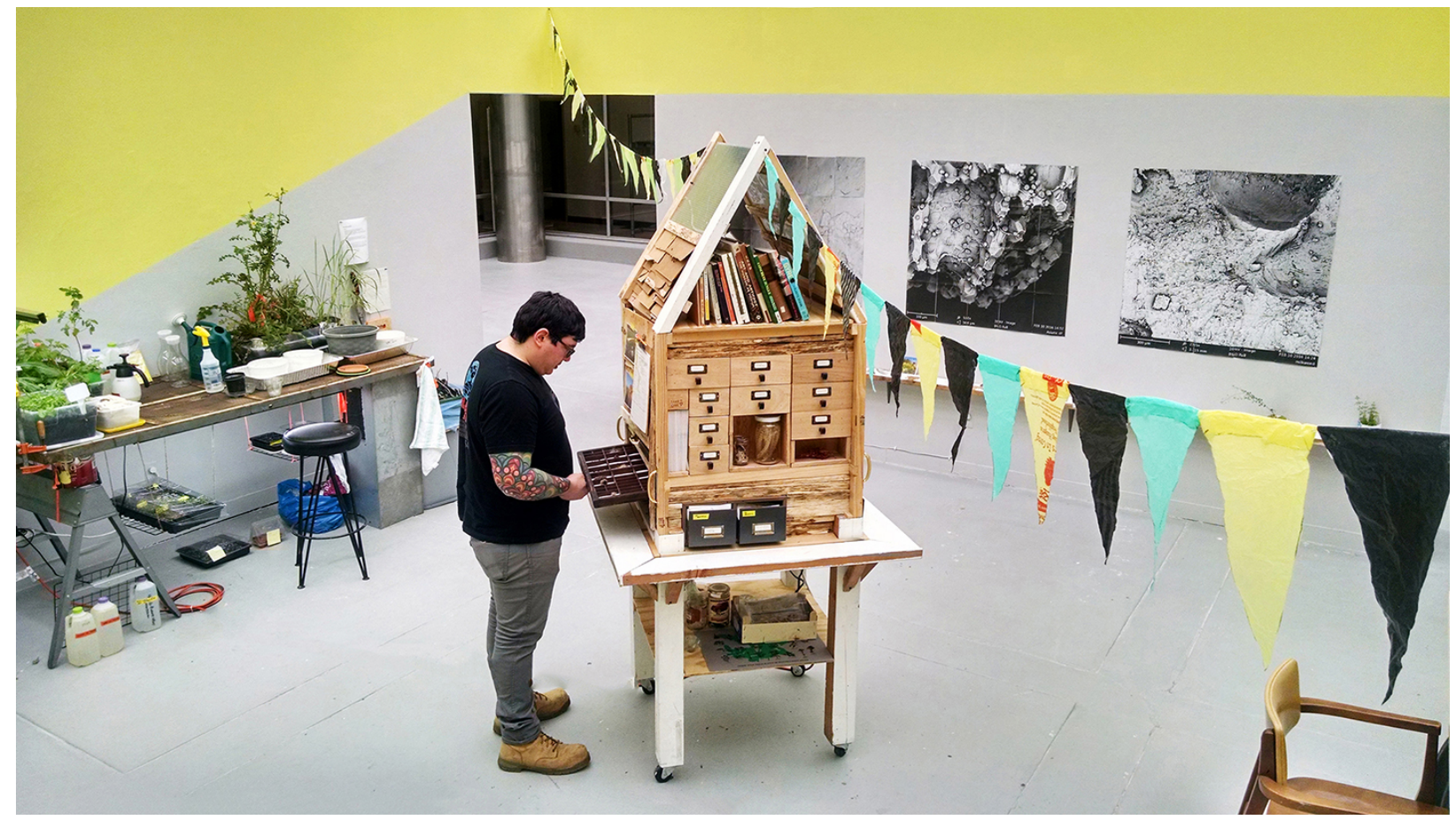

Figure 2: The Next Epoch Seed Library at William Paterson University in spring 2016 for the exhibition Nurturing Nature. This functioning, participatory library installation included a central structure housing our seed collection available for checkout, books and curriculum guides, video documentation, plant propagation and seed sorting stations, a reading area with community bulletin board, and enlarged microscopy photos of seeds in our collection. Visible here are the seed collection structure, microscopy photos, and plot propagation station.

Photograph courtesy of Anne Percoco, Next Epoch Seed Library.

In the text and multimedia essay that follow, I will begin by describing the mission and approach of NESL and how this work led us to develop a lawn rewilding project. Having introduced NESL and Lawn Lab, I will pause to explore the community of practice that has influenced our trajectory, and make a case for why this approach is relevant in the current moment. This community of practice is composed of artists who, in my view, take a critical, ecosocial approach to art making that emphasizes plant-human entanglement. With this context established, I turn to a more in-depth discussion of the pilot season of Lawn Lab, including our motivations for creating the project and the process through which it was realized. In the final section, I turn to Georgina Born and Andrew Barry's (2010) concept of the "public experiment" as a lens through which to analyze my experiences implementing the pilot season of Lawn Lab and some of the takeaways that arose from the workshops and fieldwork sessions we facilitated. I close by concluding that the conversations and exchanges that came to the surface as we implemented the first season of the project make a worthwhile case for further seasons, which could be approached with a more rigorous system for soliciting feedback and measuring ecosocial impact, with the goal of eventually creating permanently rewild plots in lawns that have hosted the project. 
In 2015, when Anne and I founded NESL, we reimagined the conventional seed library as we understood it. Instead of limiting our focus to agricultural and horticultural species, we opened it up to the interlopers of the plant world: those weedy species that have evolved to live in close association with humans but that are often unwanted. In doing so, we found ourselves interrogating assumptions around nativeness, belonging, and plant-human reciprocity in the face of a changing climate. Using walks, workshops, and pop-up libraries, we experimented with developing accessible and pleasurable situations for connecting urban-dwelling humans and weedy plants. Along the way, we came to know the weedy species we live alongside in new ways. Reflecting the cosmopolitan human population of our metropolitan area, the spontaneous urban plants of New York City hail from around the world. Whether native or introduced, they possess ecological adaptability, nutritional attributes, and healing properties that have been overlooked, forgotten, and even demonized in many strains of contemporary Western culture (Del Tredici 2014; Geniusz 2015; Castañeda-Álvarez et al. 2016). In solidarity with a rising tide of weed enthusiasts, and in deference to the Indigenous and immigrant communities that have stewarded this botanical knowledge over centuries of colonization and industrialization, we committed ourselves to relearning our relationships with weedy plants through the lens of reciprocity rather than animosity (Phillips 2017; Irons 2017).

From Robin Wall Kimmerer's (2015) call for biocultural remediation to Anna Tsing's (2011) ethnography of weediness, many scholars have explored how enacting reciprocal relationships with plant-beings has a significant role to play in human culture and sociality. Others have described how alienation from these reciprocal relationships has led to lamentable situations like the socalled "war on invasive species" and the ongoing arms race between corporate herbicide producers and weedy resistance (Orion and Holmgren 2015; Moore 2015, 273-74). In contemporary urban ecosystems, widespread impervious surfaces and zealously manicured parks can make opportunities for connecting with plant life seem limited. It takes some effort, unlearning, and repatterning to see the many weedy plant species that live alongside us in the city. NESL works to develop artistic practices that can provide one entry point for beginning that process.

Although NESL works in an artistic context, our efforts are in direct dialogue with the missions of other seed-saving institutions operating beyond the arts. Like the Svalbard Global Seed Vault, in Norway-dedicated to saving agricultural seeds deep underground for posterity-we are interested in longterm storage and genetic diversity (Westengen, Jeppson, and Guarino 2013). We also align ourselves with the motivations of community seed storage and trading efforts that reclaim the autonomy of informal and community seedsaving cultures from corporate and private control, as practiced by groups like the Seed Savers Exchange (SSE) and the White Earth Land Recovery Project's Indigenous Seed Library (SSE n.d.; WELRP n.d.). Both of these approaches 


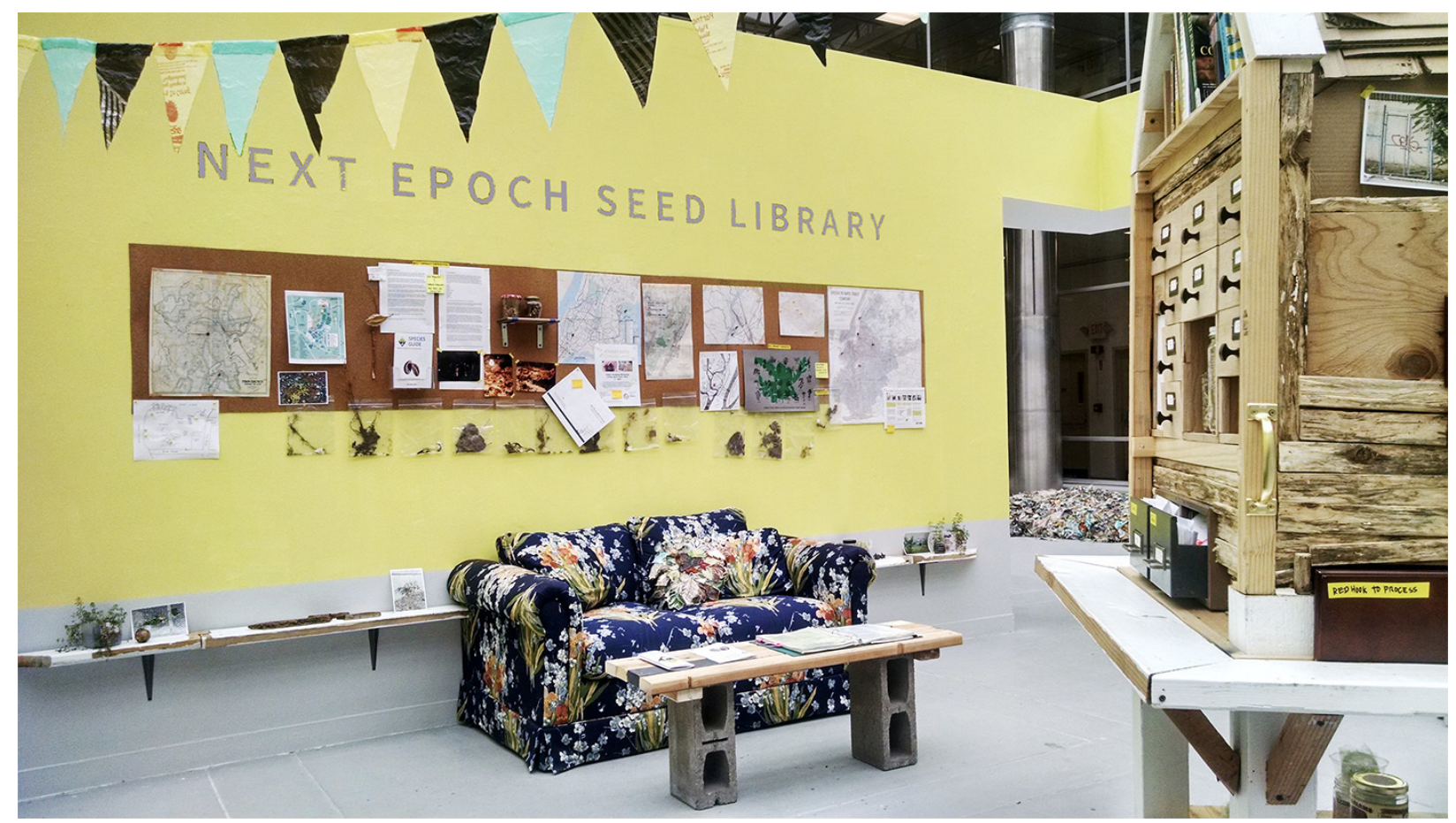

Figure 3: A second view of NESL's library installation at William Paterson University. Visible here are the reading area and the community bulletin board.

Photograph courtesy of Anne Percoco, Next Epoch Seed Library.

have roles to play in nurturing future possibilities for plant-human thriving. We see NESL as working in the gap between the two, challenging normative conceptions of what is useful, practical, and desirable to save and steward for the future. Our logo reflects this idea. Anne designed it as a riff on the aboveand belowground nature of plants and seed libraries. Just as plants live a dual life above- and belowground, our seed collection is both available to the public for circulation and stored long-term, out of circulation, or "belowground."

As NESL has evolved over the past four years-branching out to include deep time seed burial projects and seed redistribution networks-we have retained a commitment to working in habitats described variously as postindustrial, disturbed, and ruderal. ${ }^{1}$ Increasingly, these sites are being recognized as lively zones full of novel ecological relationships, providing insights into how ecosystems might evolve under extreme environmental conditions (Hobbs, Higgs, and Hall 2013; Stoetzer 2018). For NESL, these settings provide a widespread and accessible habitat type in which to seek methods to adapt and thrive together across cultures and species in the face of a changing climate.

1 Ruderal, from the Latin for rubble ( $(r u d u s)$, is a botanical term used to describe plants living in disturbed landscapes ("among rubble"). Its application has expanded to include disturbed landscapes, especially those that are depleted, polluted, and fractured by human activity (Stevenson 2010). 


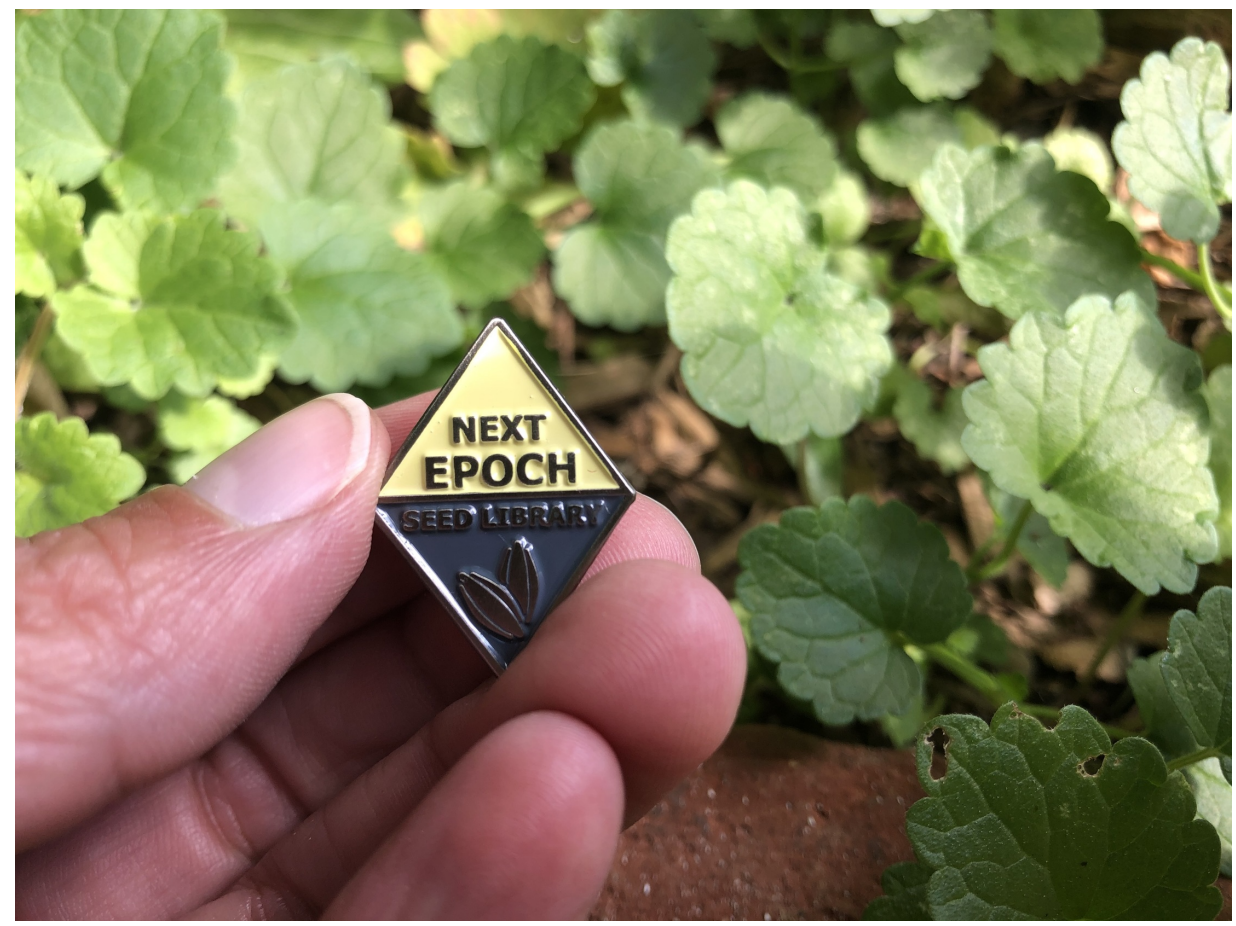

Figure 4: NESL's logo, seen here in the form of an enamel pin offered to members who participate in public programming and other seed library activities.

Joining scholars of urban geography, landscape architecture, and urban ecosystems, we see ruderal landscapes as "informal green space" capable of providing benefits ascribed to formal parks and gardens, while also supporting a diverse and complex example of how multispecies communities can be woven into urban life (Del Tredici and Pickett 2010; Rupprecht 2017). We also recognize that in a future that will see the majority of the earth's human population dwelling in cities, working in ruderal sites requires a justice-based approach to environmentalism that seeks guidance from feminist, decolonial, Indigenous, and multispecies perspectives in striving for the most equitable version of that future possible. Across our activities, we combine socially engaged art, urban ecology, and multispecies pedagogy in pursuit of ecological justice through solidarity with the more-than-human. ${ }^{2}$

With the launch of Lawn Lab in 2018, NESL expanded its focus from sidewalk cracks and Superfund sites to include another kind of disturbed habitat: the ubiquitous American lawn. For NESL and others who share our approach, this widespread habitat type is both a symbol and a physical instantiation of destructive settler-colonial approaches to controlling and dominating the landscape (Robbins and Sharp 2006; Ellis 2017). As white, settler artists active in the northeastern United States, grappling with lawns as subject and medium

\footnotetext{
2 Multispecies pedagogy is an embodied form of teaching and learning that cultivates cross-species exchange and knowledge production. The term has some precedents beyond my usage here, mostly in the context of early childhood education and multispecies ethnography, both of which are also relevant (Kirksey and Helmreich 2010; Taylor and Pacini-Ketchabaw 2015).
} 


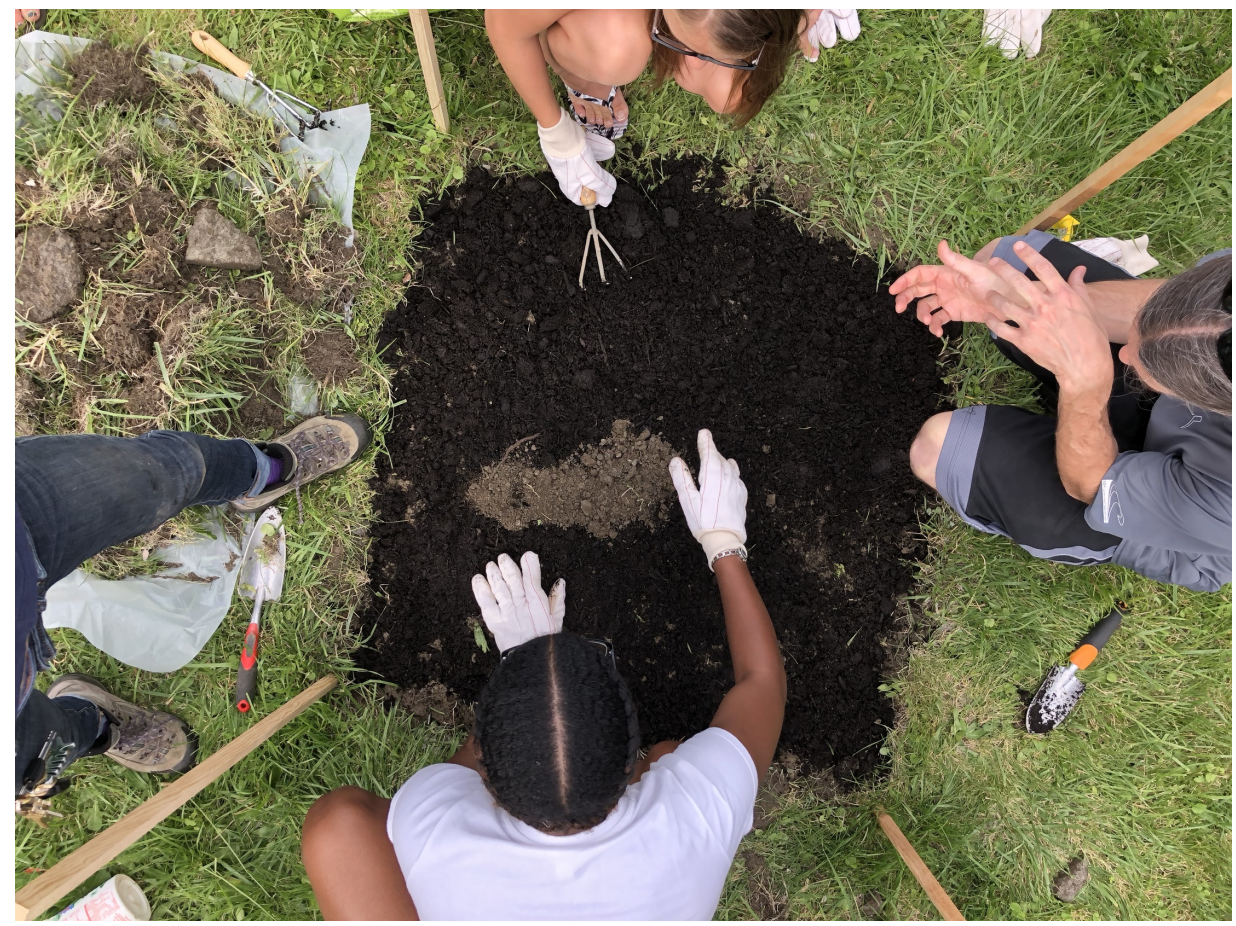

Figure 5: Participants preparing a plot for the Lawn (Re)Disturbance Laboratory as part of a workshop with Community Miracles in Action and the Sanctuary for Independent Media's NATURE Lab, Cohoes, New York, June 2018.

is a way to contend with our own complicity in the systems that have made these habitats so prevalent. Through public-facing sculptural interventions, ecology fieldwork, and community science, Lawn Lab creates opportunities for enacting different relational possibilities in and with lawn-based habitats. In dialogue with a rich history of lawn-disrupting artistic practices, we offer our version: a series of rewilding interventions in institutional and residential lawns that centers plant agency by activating seeds lying dormant in the soil. ${ }^{3}$

\section{NESL's Place in a Community of Practice: Critical, Ecosocial Approaches to Weedy Entanglement}

While this essay focuses on the Next Epoch Seed Library and Lawn Lab, our approach has co-evolved in dialogue with a range of projects and practitioners with whom we have reciprocal creative entanglements. ${ }^{4}$ Indebted to and in conversation with the broader field of eco-art, and responsive to fields ranging from feminist performance art to restoration ecology, this community of practice shares a particular commitment to hands-on, relational work with vegetal life-forms in urban and disturbed habitats. While echoed and

\footnotetext{
3 Examples of related lawn-oriented artistic precedents range from Fritz Haeg's Edible Estates (Allen et al. 2010) to Mei Ling Hom's Invasive Aliens. Since founding Lawn Lab we have also learned about Lois Weinberger's similar experiments, including his 2017 installation Ruderal Society: Excavating a Garden for Documenta 14 in Kassel (Germany), and about Brian Collier's Unlawning America project.

4 NESL's approach has been deeply influenced by engagement with related initiatives active in the Northeastern United States, including curatorial platforms like Chance Ecologies and Emergent Ecologies, and artist collectives and projects like The Environmental Performance Agency, The Collaborative Urban Resilience Banquet (C.U.R.B), and Guerrilla Grafters. We have also recently been inspired to learn about Maria Theresa Alves' ongoing Seeds of Change, Gaye Chan and Nandita Sharma's Eating in Public, and the long running work of the collective SPURSE.
} 
prefigured in other fields and practices, the work we do together is context specific and urgently responsive to contemporary conditions in Western, settler-colonial societies under late capitalism, with a particular eye toward the strengths and failures of environmentalism in the American context (Guha 1989; Heise 2008).

Like NESL, others in this community of practice combine urban ecology and socially engaged art in ways that evidence a critical, ecosocial approach to art making that foregrounds reciprocal exchange with vegetal life-forms in urban and ruderal habitats. ${ }^{5}$ This approach puts us in dialogue with scholarship and practice arising from feminist science and technology studies (STS), decolonial studies, and multispecies ethnography. ${ }^{6}$ As in Donna Haraway's naturecultures, to be ecosocial is to refuse to separate ecological and social systems (Haraway 2003, 6). To be critical, as in Val Plumwood's (1994, 1-4) critical ecofeminism, is to be attentive to flows of power and privilege both in our immediate practices and in the systems that shape them. And while the ecofeminist roots of the contemporary challenge to the nature/culture divide emerged in the 1980s and '90s, Métis artist and writer Zoe Todd (2016) makes the essential point that these ideas themselves, while slowly entering Western science, and now hailed as an "ontological turn" in the humanities, have long formed the basis of many Indigenous cosmologies worldwide. As we learn from the plants that inhabit our urban ecosystems, we also have the responsibility to acknowledge our complicity in their existence. They would not be here, doing what they are doing, without us. Along with this realization comes the responsibility to seek out and hold space open for the knowledges and lifeways that have been marginalized and occluded by the processes that have brought this landscape into being. Approaching these issues through physical engagement with weedy life-forms provides a fresh entry point for cultivating forms of environmental consciousness suitable for navigating the strange time we inhabit.

Whether we call it the Anthropocene, the Chthulucene, the Capitalocene, or simply climate chaos, it is undeniable that the cumulative impacts of centuries of colonization, industrialization, and unchecked growth are pushing naturalcultural systems to the brink (Shiva 2006; Haraway 2015; H. Davis and Todd 2017; Meyer 2019). Challenges like these call for an all-hands-on-deck approach to working toward livable futures in the face of what has been and will continue to be a long and protracted crisis. As an artist, educator, and amateur ecologist, I have a particular set of skills and passions I am driven to use in the face of this daunting crisis, and I have found this drive reflected

\footnotetext{
5 Uses of "ecosocial" and "eco-social" in relationship to recent and contemporary artistic practices that relate to my own include Ireland-based artist Cathy Fitzgerald's eco-social art practice, and the mission of the artist collective Third Space Galway, which describes itself as an “interdisciplinary ecosocial arts collective” (Fitzgerald 2019; Third Space Galway 2019).

6 Taking "a fresh emphasis on the subjectivity and agency of organisms whose lives are entangled with humans," the relatively new field of multispecies ethnography draws on environmental studies, STS, and animal studies to remake conventional anthropological approaches to the nonhuman world (Kirksey and Helmreich 2010, 545).
} 
in other artists with related and complementary skill sets. This has led me to work collaboratively, gradually identifying strategies through which I can join many allies in cultivating forms of environmentalism that are intersectional in nature. ${ }^{7}$ From the new Poor People's Campaign to the struggles of Indigenous water protectors and their allies, movements that foreground the tightly intertwined nature of environmental degradation and injustice are gaining momentum. It is essential to advocate for and make visible these forms of environmentalism in an era that has seen the reemergence of reactionary and exclusionary environmentalisms premised on nationalism, white supremacy, and human exceptionalism (Out of the Woods 2018; Krzeminski 2019; Fisher and Achenbach 2019). This is a challenge I believe contemporary, environmentally oriented artists of my positionality have a responsibility to address.

Following adrienne maree brown's (2017) call for “emergent strategy," I see the work happening among the community of practice I have described as one means of contributing to larger, movement-level goals aimed at systemic change. Intimate, community-scale interactions and interventions that take a critical, ecosocial approach to cultivating vegetal attunement and entanglement connect, resonate, and reverberate with related practices, amplifying one another. Key to the efficacy of this approach is a shared understanding that undoing the forms of human supremacy embedded in many post-Enlightenment Western cultures is one essential ingredient in building more just, livable futures (Whyte n.d.; Crist 2019). For NESL, one hands-on place to start this work is with one's local lawn landscape.

\section{Implementing the Pilot Season of Lawn Lab: Will You Lend Us Your Lawn?}

Lawn Lab was launched in 2018 in Troy, New York, a postindustrial city two hundred miles north of NESL's home base in New York City. The project provides a useful case study for relating how the critical, ecosocial approach theorized above works in practice. I will use the remaining portion of this essay to describe how the project's first season unfolded, exploring the benefits of open, publicly accessible exchange between art and ecology, and between humans and other life forms. In doing so, I will respond to Georgina Born and Andrew Barry's 2010 article "Art-Science: From Public Understanding to Public Experiment," in which these scholars of interdisciplinary collaboration explore how art-science projects can illuminate and expand scientific processes to connect to the social and the political.

\footnotetext{
7 Environmentalism grounded in a justice-based approach is intersectional in that it takes into account layered forms of oppression as articulated in black feminist theory, in particular by legal scholar Kimberlé Crenshaw (1989). For a discussion of intersectional environmentalism see Rob Nixon's Slow Violence and the Environmentalism of the Poor, which includes an analysis of how Kenya's Greenbelt Movement (a woman-led, activist tree-planting project co-founded by Wangari Maathai) broadened "their base and credibility by aligning themselves with—and stimulating - other civil rights campaigns...for women's rights, for the release of political prisoners, and for greater political transparency” (2011, 138-41).
} 


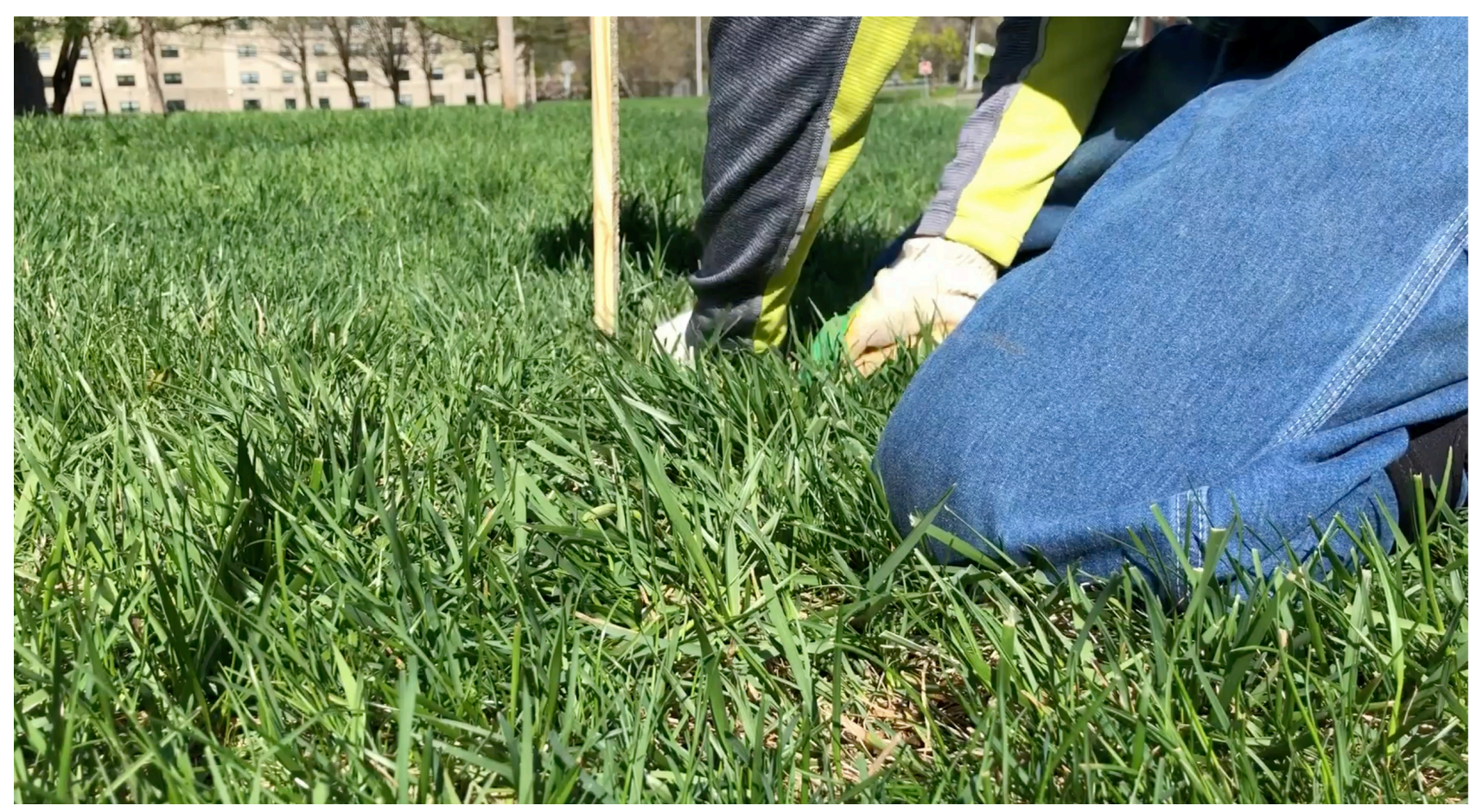

Figure 6: Video documentation of the establishment of Lawn Lab plot \#1 on the campus of Rensselaer Polytechnic Institute in March 2018. This plot was sited on a patch of lawn between two access roads and a parking lot.

Video available at: https://vimeo.com/432701579/0db272083c

Lawn Lab is a natural outgrowth of NESL's work with weedy seeds and time. We have long been intrigued by the ability of seeds to stay dormant for long periods of time, seemingly inert, but still alive, waiting for the right conditions to sprout. Through our own experiences with soil and seeds, and through perusing scientific articles, we learned that seeds from certain disturbanceoriented plants can stay dormant for decades or even centuries (Telewski and Zeevaart 2002). Seeds that remain dormant in the soil are known as the soil seed bank. These seeds do not necessarily reflect the species composition of aboveground vegetation and are even present in soils where vegetation no longer exists, such as below asphalt or under glaciers (Albrecht et al. 2011). Many questions regarding how dormant seeds effect ecosystem recovery remain to be answered, but it is clear that "persistent seed banks" play a role in adaptation to disturbance (Kalisz 1990). We use this phenomenon to reframe lawns as ecosystems suffering protracted disturbance and in need of a fresh (re)disturbance to jump-start the process of healing. Through the simple act of removing turf from a portion of lawn, we see an opportunity to kick off a plant-led rewilding process from the soil seed bank.

Lawn Lab engages a well-known phenomenon in ecology and attempts to make it visible and accessible by applying it in an unexpected way. In ecology and botany, the term pioneer is used to describe plants that respond to disaster and disturbance, sprouting rapidly in bare, exposed, or otherwise devegetated earth to jump-start the process of ecosystem recovery (Allaby 2015a). Unlike the human pioneers of American colonial expansion, these so-called plant 


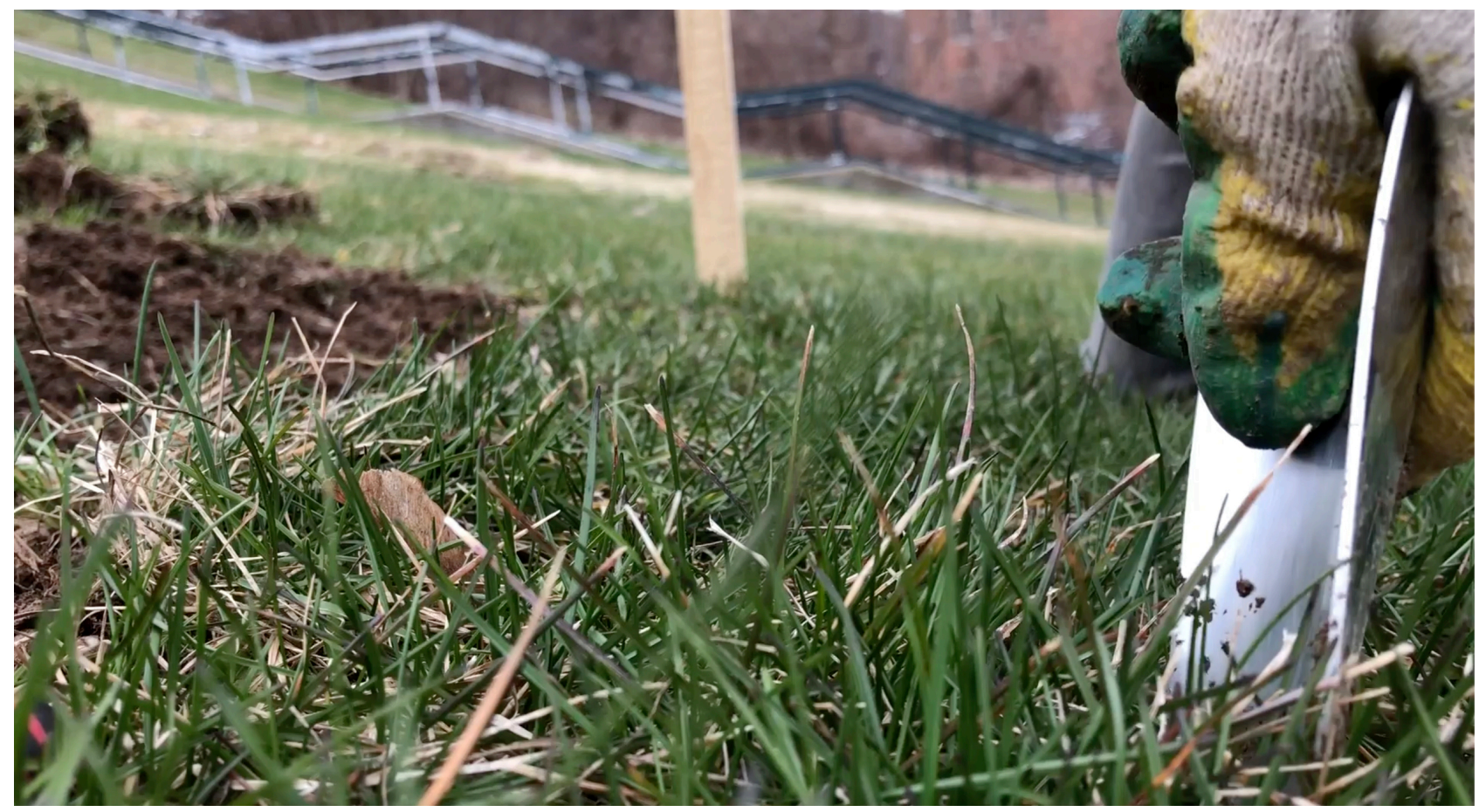

Figure 7: Video documentation of the establishment of Lawn Lab plot \#2 at the western edge of RPI's campus near downtown Troy in March 2018. This plot was sited on a large lawn that had been converted from forested land within the last decade.

Video available at: https://vimeo.com/432701742/891bfe528e

pioneers appear in large numbers and grow rapidly, but their tenure is temporary. They stabilize soil and generate habitat until slower growing species that require less exposed conditions arrive; then they retreat gradually, leaving a legacy in the soil seed bank that stays dormant for generations, until similar disturbance conditions occur again. This process, involving waves of differently adapted species that change over time, often cyclically, is known in ecology as succession (Allaby 2015b). In our lawn-as-disturbance framing, lawn maintenance disrupts the cyclical process of succession, freezing it in an idealized aesthetic that blankets ecocidal tendencies in a coating of smooth, green civility.

Much has been written about the American relationship to lawns, and while a thorough review of that literature is beyond the scope of this essay, lawn maintenance is linked to the contentious issues around class, private property, and moral uprightness perpetuated by a dominantly white, settler-colonial culture (Robbins 2007; Pollan 2003). Lawns and the values they represent persist even as more and more evidence shows that using land this way is actually detrimental to the social-ecological health of cities large and small. Unlike other forms of green space, conventional lawns reduce biodiversity, emit more carbon than they sequester, and, depending on treatment regimes, expose local human and nonhuman populations to toxic chemicals ( $\mathrm{Gu}$ et al. 
2015). For NESL, they also represent the ongoing violence of settler-colonial domination of so-called wilderness, and a tragic waste of resources in the face of an extinction crisis.

In many small and medium-sized American cities, lawns of all varieties are ubiquitous, making up a large percentage of urban green space (Ignatieva et al. 2015). Troy, a postindustrial city of sixty thousand on the Hudson River north of New York City, is no exception. Founded in 1789 on Mohican land, Troy was an industrial center for more than a century [@28905;(Martin n.d.). Today, lawns fill in the abundant gaps where industry has shrunk away, flank single-family homes and apartment buildings, and surround public and private institutions. As in many cities, regular mowing is mandated by a city ordinance that puts a height limit on vegetation. Troy's code singles out weeds, in particular, declaring it "unlawful to allow or maintain on any lot [...] any growth of weeds over six inches," where weeds are defined as "anything in the ambrosiaceae family" as well as, vaguely, "All rank vegetable growth which exhales unpleasant odors and also high and rank vegetable growth, which may conceal filthy deposits" (City of Troy n.d.). Short, neat lawns are deemed clean and safe, while wild or feral plants are dangerous and dirty, and this value system is enshrined in the city code.

With the city's code and its implications in mind, NESL approached a range of lawn-wielding institutions and individuals in the winter of 2018 and invited them into what we presented as a simple, low-stakes collaboration. We framed the collaboration as a journey of discovery: if they would lend a one-by-one meter, publicly visible patch of lawn to the project, together we could discover what seeds might be sleeping beneath it. We got a surprising range of acceptances and capped the first season at ten plots because of capacity. The sites ranged from pristine, carefully maintained turf grass at Rensselaer Polytechnic Institute (where I am a PhD student) to lightly maintained fields in so-called vacant lots. By the end of May, in addition to vacant lots and university lawns, we had established plots in a churchyard, in front of a convenience store, in a community park, and in the side yard of a two-family home. We set to work redisturbing lawns and testing the limits of the city's tolerance for vegetation over six inches high.

In addition to the publicly visible plots, every step of Lawn Lab-from soil sampling to plot establishment to redomestication at the end of the season-was offered as a public event or workshop in collaboration with a local institution. At each site we began by collecting soil samples, which were stored for later sprouting under controlled conditions according to soil seed bank sampling protocols. Data was collected throughout the growing season about what plants sprouted in which soil samples. This part of the project was carried out at NATURE Lab, a local community art-science organization run by the Sanctuary for Independent Media. 


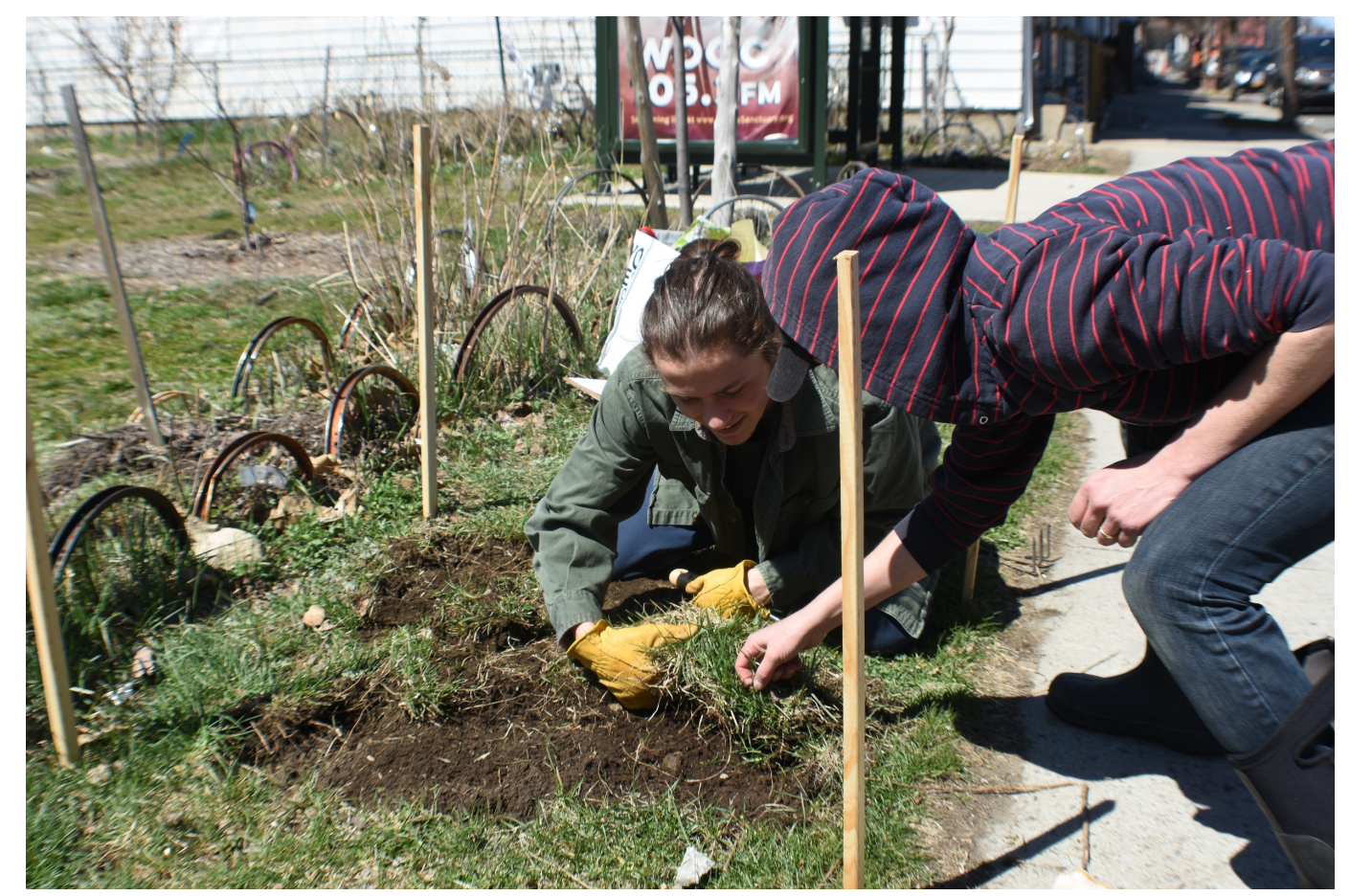

Figure 8: Workshop participants establish Lawn Lab plot \#9 at the Sanctuary for Independent Media's Freedom Square (6th Avenue and 101st Street), April 2019. The site pictured here has been lawn for at least forty years, according to documentation held in the Sanctuary's archives.

Photo courtesy of Lawn Lab participant Luke Batemen.

Once soil samples were collected, it was time to establish plots. Of the ten plots, four were established in workshop settings. Workshop participants engaged not only in the physical labor of removing turf but also in the intellectual labor of contending with themselves as agents of disturbance. Before pulling up the turf, we familiarized ourselves with the turf as an ecosystem and life-form in its own right. We carried out turf and plant attunement exercises and read a "lawn (re)disturbance acknowledgement" aloud.

We then turned to the satisfying and physically challenging task of pulling up turf. While participants worked on the turf in pairs, using hand rakes and trowels, others kept an eye out for insects and other soil dwellers, who were removed to a safe location and returned to the soil once the plot was established. With the turf cleared, each plot was marked off with stakes and flagging, becoming a kind of minimalist sculpture of bare soil in a sea of green. At each site we added a Lawn Lab sign. Text clearly legible at a distance read "What's Happening Here? LAWN RE-WILDING" in bold type. Smaller, supplemental text that could be read from within a few feet of the plot described the project and provided a URL, http://nextepochseedlibrary.com/ lawn, for more information.

Over the following months, the soil seed bank came to life, disrupting our minimalist squares with vibrant growth. By late August, the plots were fully vegetated with a wide variety of plant life, creating a stark contrast with the lawns that surrounded them. Throughout, I worked with volunteers and 

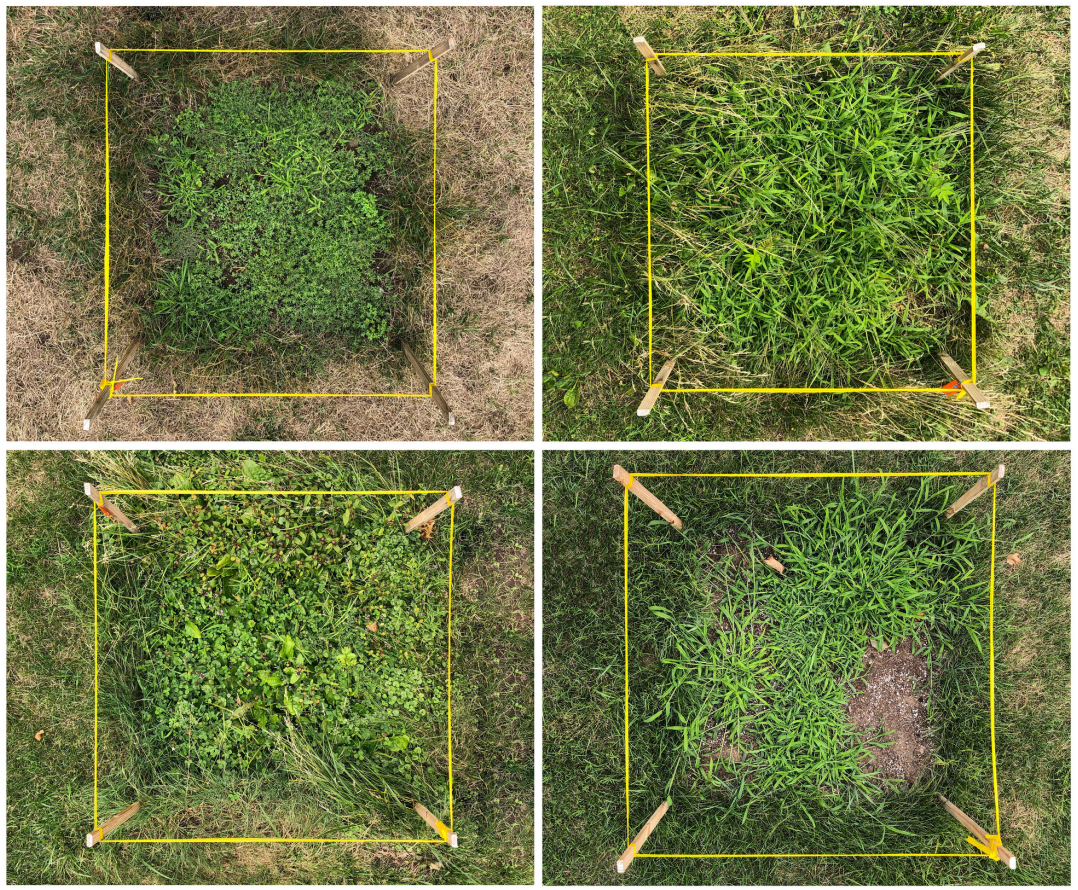

Figure 9: Lawn (Re)Disturbance Laboratory plots as seen from above, summer 2018. Counterclockwise from top left: plot 1 (Rensselaer Polytechnic Institute, Sage Avenue and 9th Street); plot 4 (Rensselaer Polytechnic Institute, Nason dormitory lawn); plot 5 (Rensselaer Polytechnic Institute, Detroit Avenue and Georgian Terrace); plot 8 (privately owned lot, North Central Troy, Ingalls Avenue and River Street).
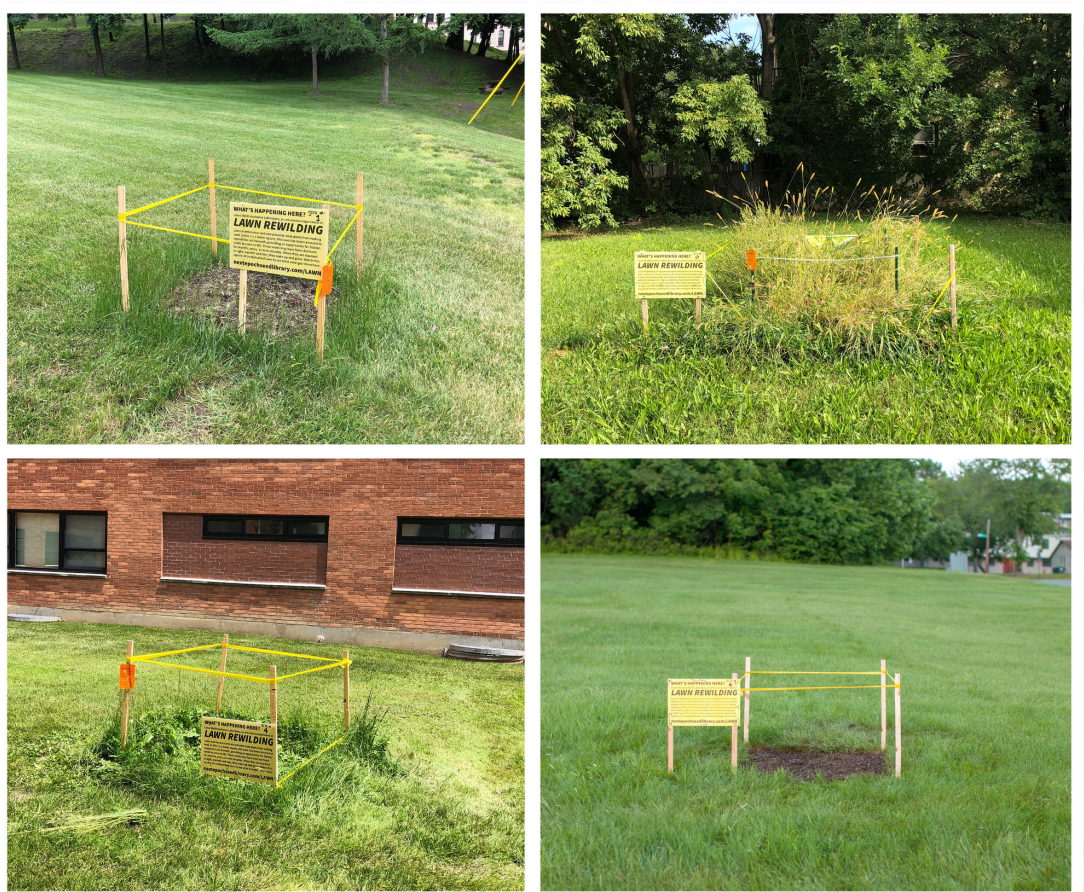

Figure 10: Lawn (Re)Disturbance Laboratory plots, summer 2018. Counterclockwise from top left: plot 1 (Rensselaer Polytechnic Institute, Sage Avenue and 9th Street); plot 4 (Rensselaer Polytechnic Institute, Nason dormitory lawn); plot 5 (Rensselaer Polytechnic Institute, Detroit Avenue and Georgian Terrace); plot 8 (privately owned lot, North Central Troy, Ingalls Avenue and River Street). 


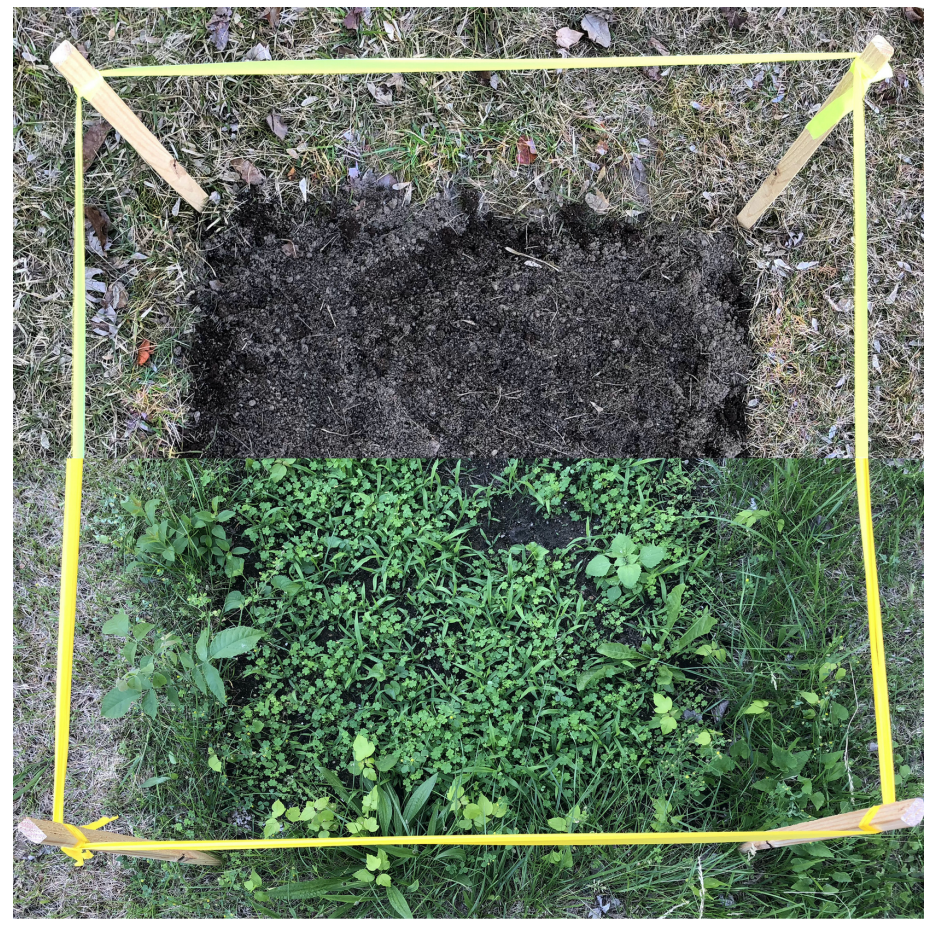

Figure 11: Lawn Lab plot \#10 (private yard, South Troy, Ida Street and 5th Avenue), as seen on the day of disturbance and six weeks postdisturbance, March and May 2018. Before (re)disturbance the lawn where the plot was established harbored four plant species. By the time the plot was redomesticated in September 2018, fifteen species had been identified in the one-by-one-meter plot.

students to gather data on the plant species that emerged, using the community science application iNaturalist to make our results publicly accessible. At the close of the season, we gathered again to do final species counts and collect plant samples for the NATURE Lab herbarium collection. As a last step, we redomesticated the plots by removing and composting the remaining wild plants and spreading grass seed in their place.

\section{Lawn Lab as Public Experiment}

As we found through implementing this first season of Lawn Lab, each lawn is a unique habitat with its own residues and relationships, and deserves to be assessed in context. While some have important sociocultural roles to play, many are simply placeholders put in place by property owners who don't know what else to do with the earth they own and who see lawn maintenance as a responsible, even neighborly, default. Over the course of the first season, we saw that Lawn Lab can offer a publicly visible framework in which to test and challenge the neutrality of the lawn and the value systems that accompany it. It also has the potential to function as a forum in which to discuss attendant issues through workshops, fieldwork days, public presentations, and exhibitions that draw on and reframe ecological science as socially and culturally relevant in urban contexts.

Providing opportunities for scientific knowledge to overlap with and crosspollinate other knowledge forms is one of the key tenets of Born and Barry's notion of public experiment. In their article, they use Beatriz da Costa's Pigeon 
Blog - in which the artist brought together technologists, pigeon fanciers, and environmental justice advocates through a novel air pollution sensing scheme-as a case study. As exemplified in da Costa's project, bringing knowledges and practices that are often confined to specialized field sites or lab infrastructures into public space can help reset expectations for what knowledges are considered valuable and how those knowledges are discussed and shared. For Born and Barry, this approach contests a model in which "science is conceived as finished or complete, and as needing only to be communicated, understood or applied" (105), with art as the missing link to communicate or respond to a foregone conclusion. Rather than serving merely to contextualize science that has been completed, art-science projects that take this form make it possible to "forge relations between new knowledge, things, locations, and persons that did not exist before. .." (116). Under their model, art-science projects have the potential to function not just as a means of assembling a public for science but also as an opportunity for "highlighting alternative conceptions and practices of publicness" (103) in which the practice of science is entangled with and inextricable from the context in which it will be applied-that is, the public sphere.

We designed the pilot season of Lawn Lab with these tenets in mind. By creating a network of Lawn Lab plots across the city of Troy, we hoped to call attention to the ubiquity of lawns and contest their normative status. The lawn as muse and physical substrate provided a specific platform around which to unite diverse publics-from university groundskeepers to local homeowners to a range of students from a variety of backgrounds. Because the plots were sited across habitat types and in diverse geographic and socioeconomic settings, we were able to explore lawn maintenance and restoration potentials in communities with differing degrees of privilege and power. Starting with seemingly innocuous conversations around lawn care, we could make connections to larger structural issues that hold unsustainable and unjust systems in place. The following discussion provides a cursory look at some of what we learned from the pilot season of Lawn Lab. While there are other axes along which to group our Lawn Lab plots (for instance, public versus private ownership, frequency of mowing, or the age of the lawn), my preliminary exploration below groups the plots by geographic proximity. This allows questions around environmental inequity to come to the fore because Troy, like many American cities, is highly segregated by race and class (Capital District Regional Planning Commission 2019).

Five of the eleven Lawn Lab plots were sited on the grounds of Rensselaer Polytechnic Institute (RPI), which is located in a mostly white, middle-class neighborhood on a hillside above downtown Troy. Here, tremendous resources are poured into the landscape to maintain the lawns that stretch across the campus. A lawn care firm called TruGreen treats the grounds with 


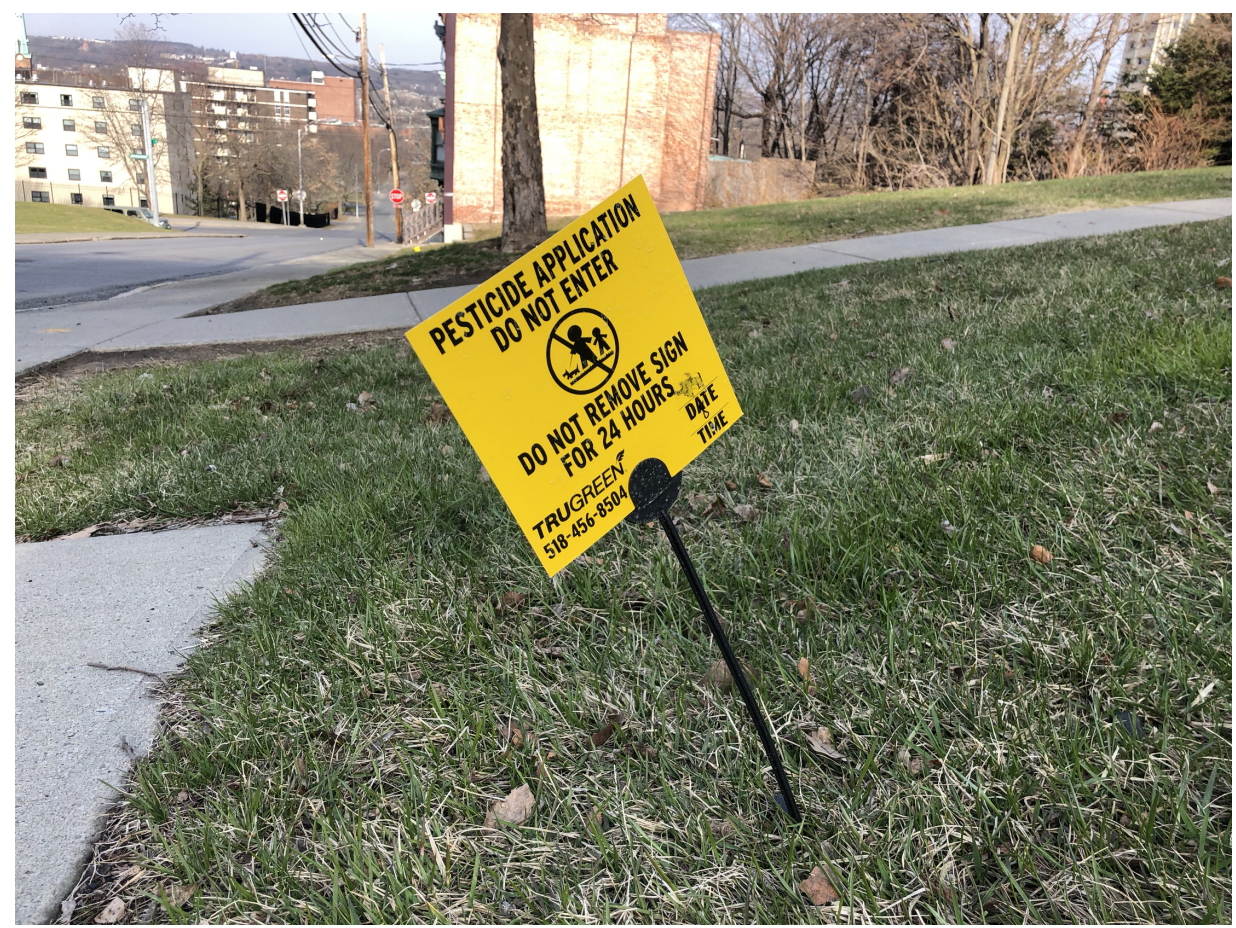

Figure 12: The maintenance of lawns at Rensselaer Polytechnic Institute includes herbicide application. This herbicide marker was photographed in April 2018 near Lawn Lab plot \#1.

herbicide, and a large team of groundskeepers employed by the university mow and spot-treat with herbicide throughout the growing season. In my two years at the university, I have rarely seen the grass more than a few inches high.

Despite this rigorous lawn maintenance regime, the majority of the plots on RPI property generated a net biodiversity gain, meaning that there were significantly more species present in the plot at the end of the season than there were in the lawn surrounding each plot. We took this gain as evidence that the soil seed bank was still intact although several of the lawns we (re)disturbed had been in place for decades. The average plot at RPI harbored one to two plant species predisturbance and ten to twelve postdisturbance. The same was true for indoor soil seed bank tests sprouted at NATURE Lab, although species composition varied widely across plots. We also observed, anecdotally, a higher variety of insects visiting the plots than were present in the surrounding landscape.

Responses to the project plots on RPI lawns were largely positive, at least from students, fieldwork participants, and those groundskeepers with whom I communicated regularly. Fieldwork gatherings at RPI provided opportunities for discussion. As we experimented with the best way to photograph delicate flowers for online identification purposes, some fieldwork participants expressed amazement that the administration and groundskeeping staff had been willing to collaborate on the project. When we noticed seemingly higher numbers of insects in the plots than on nearby lawns, some students aired concerns about herbicide use on campus, expressing reluctance to use the turf 


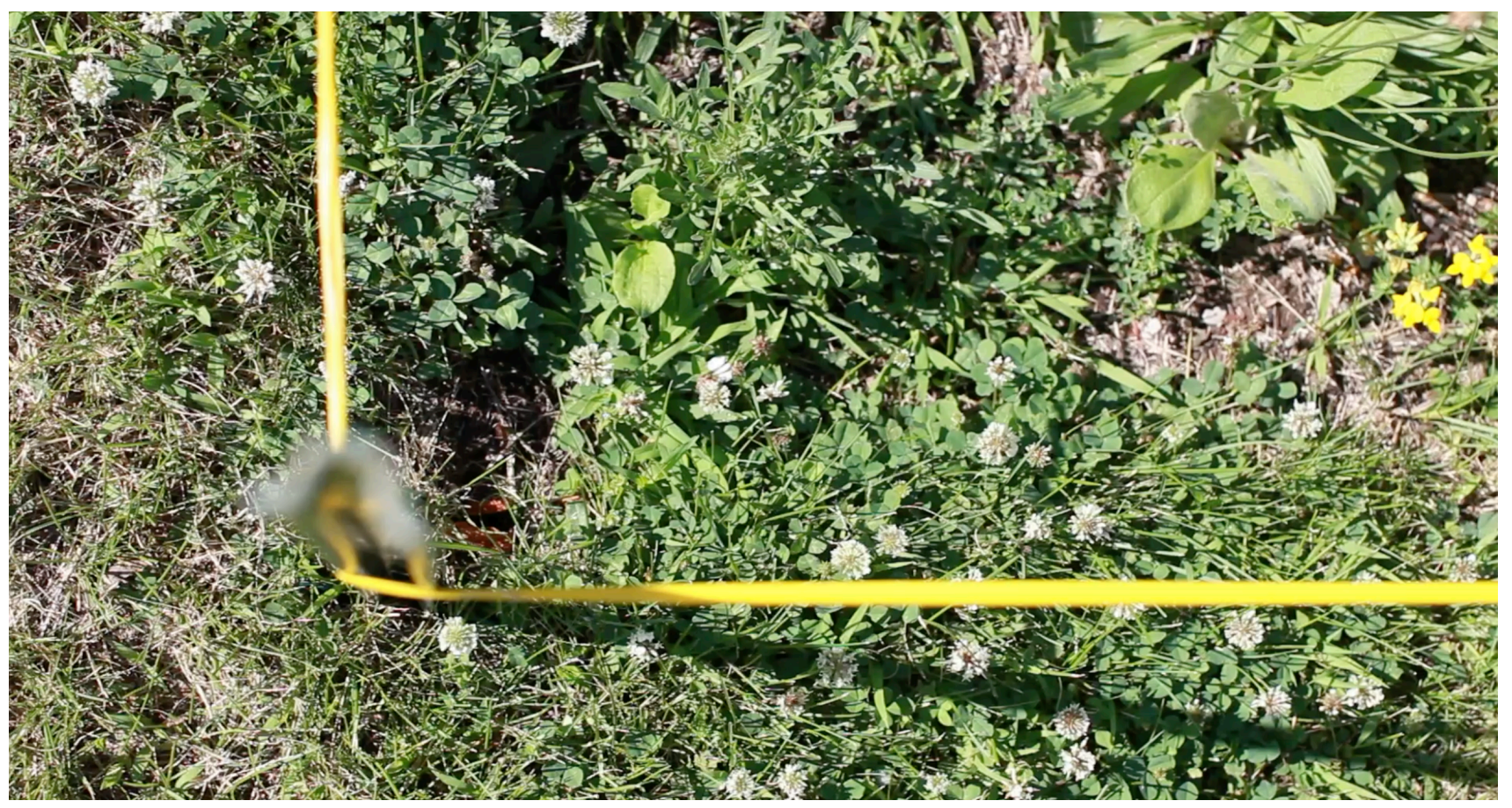

Figure 13: Video documentation of fieldwork at Lawn Lab plot \#1 in July 2018, when twelve plant species had been identified in the plot along with a range of insect visitors.

Video available at: https://vimeo.com/432701994/9616fcf59b

for leisure or recreation after seeing TruGreen herbicide treatment signs. These fieldwork sessions gave us an opportunity to envision how the landscape would change over time in terms of insect abundance, heat and humidity, and overall livability if the majority of RPI's lawns were transitioned to meadows. In coming seasons of Lawn Lab at RPI, we will explore the possibility of a largerscale, permanently rewilded lawn plot.

One Lawn Lab plot was located on a residential lawn in the racially mixed, working-class neighborhood of South Troy. Here lawns are interwoven with a mixture of single-family homes, townhouses, small businesses, and abandoned residential and industrial spaces. This plot generated a high amount of biodiversity, with fifteen species emerging from a lawn that had four present before disturbance. It also generated the most friction of any of the plots. The lawn owner was initially sanguine about the project, giving us permission to do as we pleased in their large, street-facing side yard. Over the growing season, as the rewilded plot grew to twelve and then sixteen inches above the closely shorn lawn, they began to express reservations, wondering if we could trim the plot back a bit. When we declined to do so, they decided to withdraw from the project early, requesting the plot be returned to lawn because it was "messy" and "sent the wrong message" to their neighbors. This was the only plot of the ten that did not last a full season. It was also the only plot that was behind a chain-link fence in a setting that was clearly privately owned and maintained. 


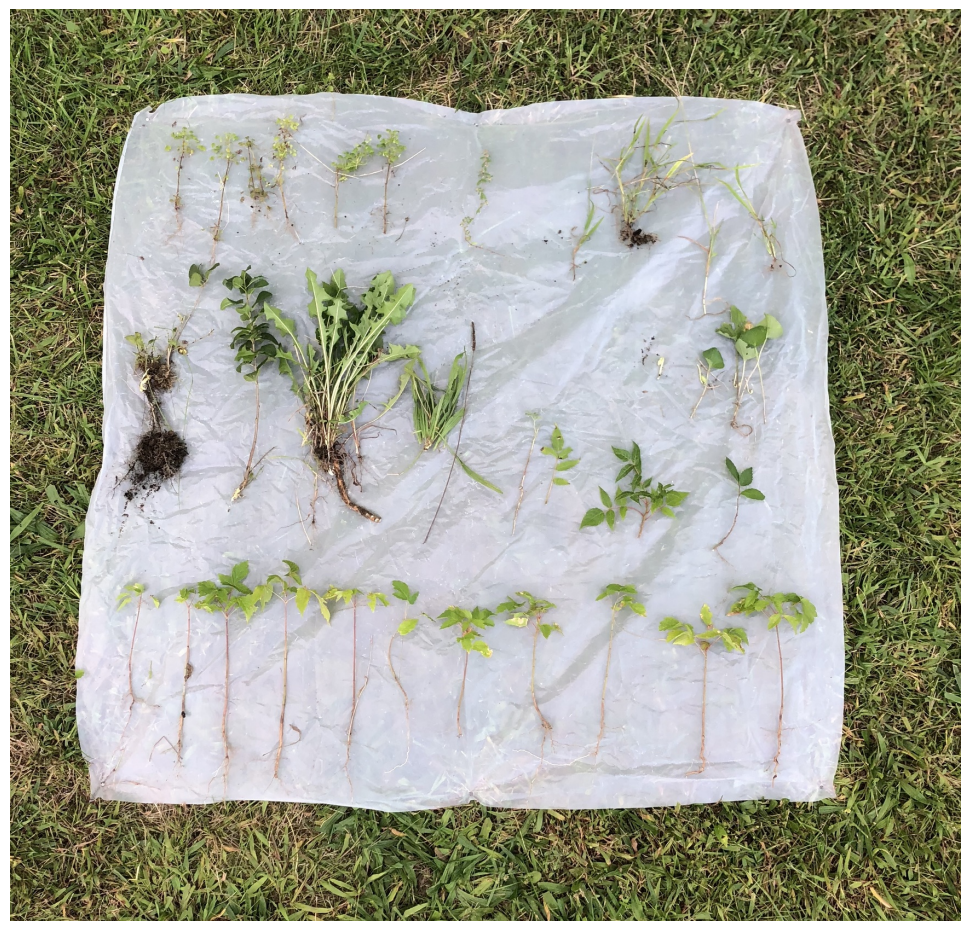

Figure 14: Plant species documented at Lawn Lab plot \#10 on the day of redomestication in early September, including (right to left, top to bottom) slender yellow wood sorrel (Oxalis dillenii), prostrate knotweed (Polygonum aviculare), smooth crabgrass (Digitaria ischaemum), common buckthorn (Rhamnus cathartica), dandelion (Taraxacum officinale), buckhorn plantain (Plantago lanceolata), eastern black walnut (Juglans nigra), tree of heaven (Ailantbus altissima), common blue violet (Viola sororia), Siberian elm (Ulmus pumila), and eleven box elder (Acer negundo) seedlings in the bottom row. Species documented in the plot but not pictured here include white clover (Trifolium repens), black medic (Medicago lupulina), corn speedwell (Veronica arvensis), and a mysterious conifer seedling that was likely dug up by a visiting skunk before it could be identified.

Three of Lawn Lab's 2018 plots were located in Troy's North Central neighborhood, on the NATURE Lab campus and surrounding vacant lots. This neighborhood includes one of the poorest census tracts in the area (Cavicchi, Anderson, and The Sanctuary for Independent Media 2018). It is inhabited largely by people of color who live with the toxic realities of life in a postindustrial city. Many people rent their homes and apartments, and there is concern around absentee landlords and deteriorating housing stock (Anderson 2018). Soil tests carried out by NATURE Lab and local residents have revealed heavy metal contamination in some locations, and the neighborhood is bordered by a portion of the Hudson River that has been declared a Superfund site due to the lingering presence of PCBs (United States Environmental Protection Agency 2019).

In our Lawn Lab fieldwork in North Central Troy, we observed that lawns are generally more diverse than at RPI, harboring a range of plants beyond grass. In these plots, biodiversity gains were less dramatic, because most plots already had four to five species growing in them before our plots were established. However, the visual impact, in the form of increased vegetal biomass, seemed to be more extreme. Plants grew faster and taller, creating patches that were visibly distinct beyond the signage and flagging that marked the plots. It is possible that this increased biomass was a result of stronger networks of perennial 


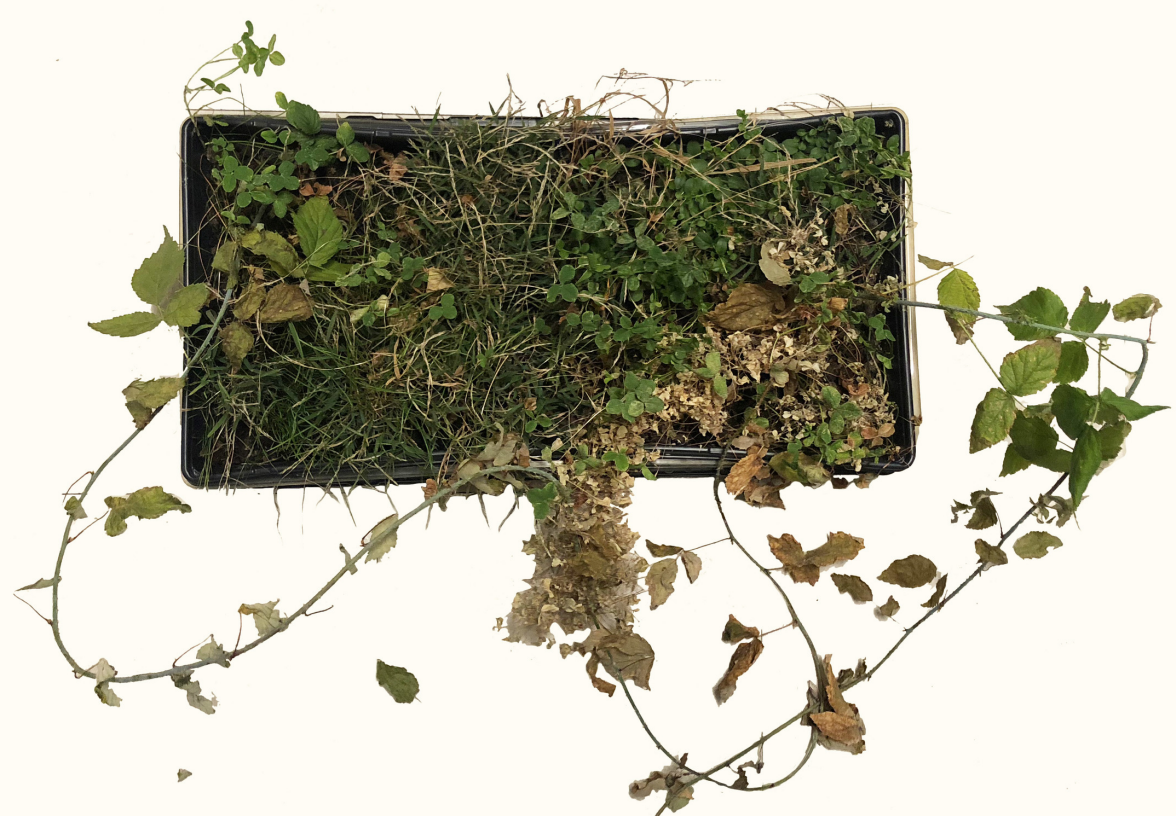

Figure 15: Indoor soil seed bank test planter, plot \#4 (Nason Hall at Rensselaer Polytechnic Institute), including eight species: smooth crabgrass (Digitaria ischaemum), white clover (Trifolium repens), prostrate knotweed (Persicaria sp.), chickweed (Stellaria sp.), raspberry (Rubus sp.), broadleaf plantain (Plantago major), wood sorrel (Oxalis sp.), and fleabane (Erigeron sp.).

and rhizomatic root structures already present in the soil under the lawns we (re)disturbed. When plants sprout as runners from a parent plant, rather than from seed, sometimes they can grow more rapidly. Indoor soil seed bank tests revealed no obvious difference in aboveground plant biomass between samples from RPI's lawns and those of North Central Troy.

In the setting of North Central Troy and the NATURE Lab grounds, we had memorable fieldwork conversations that touched on public health, neighborhood safety, and environmental justice. Through my work with NATURE Lab's summer youth program, I learned about the high incidences of asthma and elevated lead levels present in the community. As I worked with the summer youth to measure and catalog Lawn Lab plants, we talked about how full-grown plants with developed root systems hold soil in place, retain moisture, and capture particulate matter on their leaves. We could feel the coolness and relative moisture when we reached into the depths of a full-grown plot to identify a seedling or examine an insect. It was obvious that the closely cut greenery that surrounded the plots was drier and hotter. It has been shown that dry, exposed soil with little vegetative cover may result in more particulate matter, including heavy metal-laden dust, circulating in the air (Ashrafzadeh et al. 2018).

Seen in this light, the city ordinance declaring that weeds "conceal filthy deposits" took on a new meaning. Vegetation can actually trap and hold toxins, at least temporarily preventing them from circulating. It can also increase the 


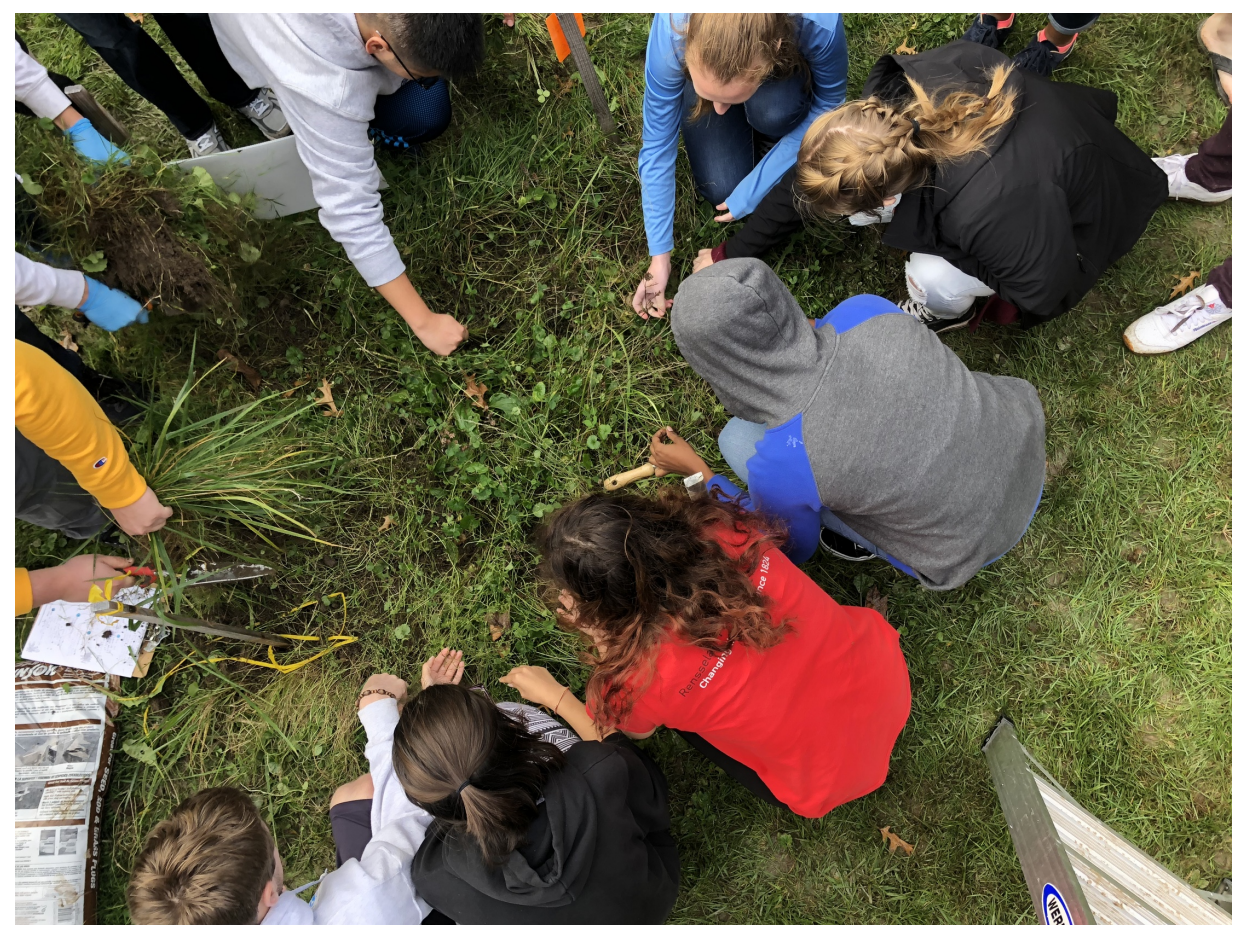

Figure 16: Fieldwork and plot redomestication at Lawn Lab plot \#4 (Nason Hall at Rensselaer Polytechnic in collaboration with Vasudah Living and Learning Community), October 2018.

ability of soil to absorb storm water runoff, leading to lower incidences of combined sewer overflow (CSO), a factor that contributes to water-quality issues in the nearby Hudson River (B. Davis 2016). I came to wonder if mowing frequently might have negative public health consequences, beyond reducing biodiversity and increasing carbon emissions, in the form of circulating dust. These are questions that are unanswered, for now, but at least have now been asked. In this way, Lawn Lab has provided a platform for imagining how a shift away from lawn monocultures and toward biodiverse wild urban plant populations could have a positive public health impact in North Central Troy. Of course, there are many other factors to consider in the face of questions around rewilding and green space, especially in underserved communities facing environmental injustice (Branas et al. 2011; Kremer, Hamstead, and McPhearson 2013). These are questions we will continue to explore as we plan and implement upcoming Lawn Lab seasons.

\section{Conclusion}

To return to Born and Barry's formulation of the public experiment, we found performing urban ecology and lawn rewilding in public as art to be generative, as they suggest. In addition to translating already established facts to another language (that is, soil seed bank science into plant-driven public sculpture), we made new knowledge together: the lawns of Troy are diverse and harbor complex soil seed banks. The ecosocial, public-facing nature of the project allowed this knowledge to be read politically and socially in ways that would 


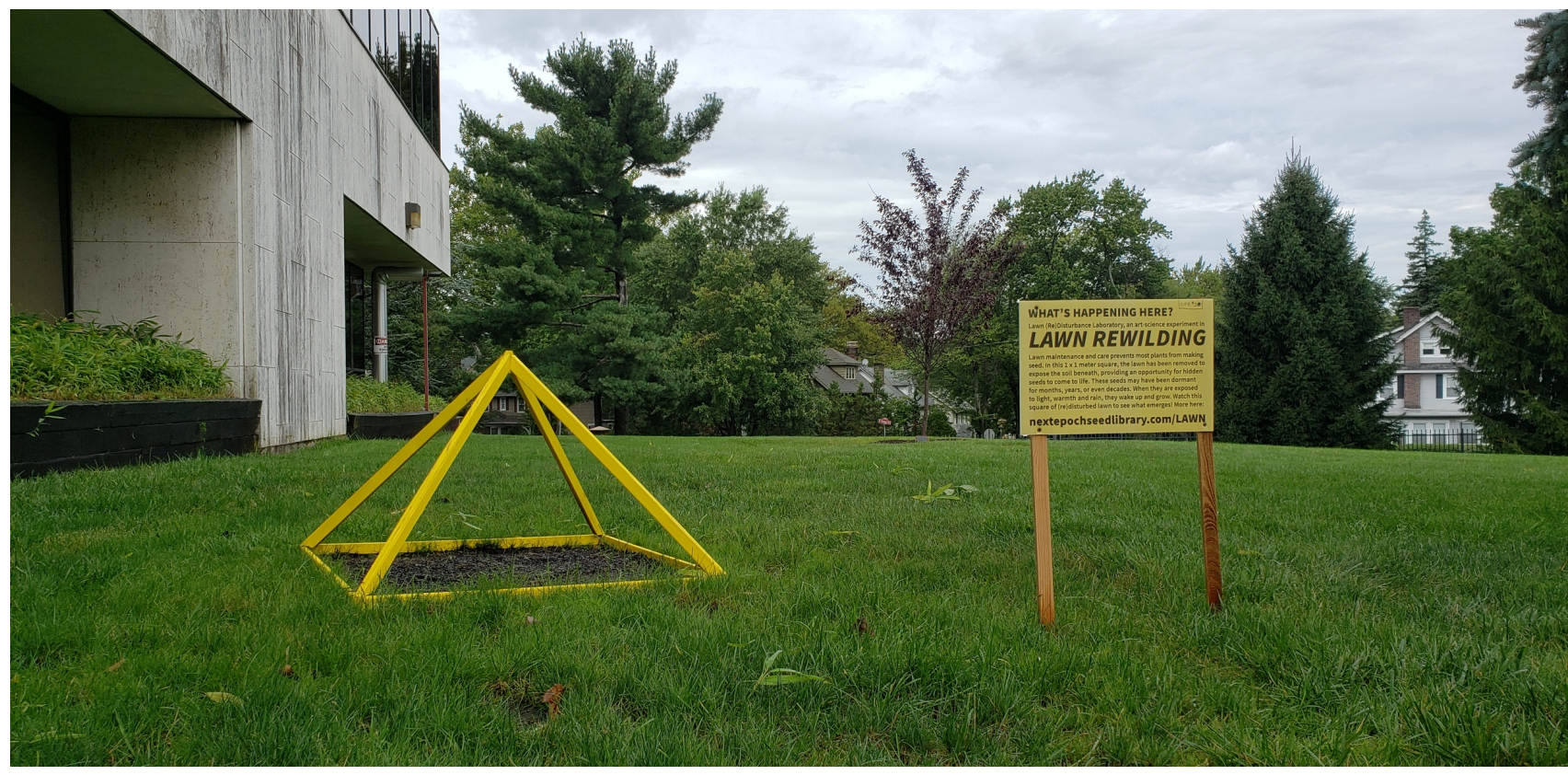

Figure 17: A freshly (re)disturbed Lawn Lab 2019 plot (season 2), on the grounds of Seton Hall University in Jersey City, New Jersey. For the second season of Lawn Lab we experimented with marking off plots with yellow pyramid structures built from scrap wood, meant to echo our logo, in this case representing the presence seeds above ground (on plants) and below ground (in the soil seed bank). We are developing this sculptural form further in the 2020 season of the project.

not have been possible were it a conventional soil seed bank experiment carried out in a lab or a more conventional public sculpture project without an ecosocial engagement component.

Connecting a constellation of artists, students, urban gardeners, groundskeepers, homeowners, renters, and nonprofit administrators allowed for a collision of ideas and perceptions around the aesthetics of cultivated landscapes and the mechanics of ecosystem restoration. Even when we disagreed, we co-generated knowledge and data-not just about plant populations but also about soil quality and toxicity, and about perceived levels of landscape maintenance and care across disparate communities. The publicly accessible maps of lawn plots and biodiversity levels, lists of plants, and notes on insect populations we produced provide an alternative lens through which to view Troy's urban ecosystem.

As NESL moves ahead with new phases of the project, we continue to ask questions about how public experiments like this one can generate knowledge and information (and more questions!) that can be reinvested in the community that generated them in productive and mutually beneficial ways. For instance, as we consider establishing permanently rewilded plots in coming seasons (with wild plants growing well over Troy's six-inch limit), we may have the opportunity to work with participating property owners to challenge Troy's regulations around wild plants, with the goal of creating a more flexible, context-responsive code. Working at the regulatory level would provide yet another avenue through which to contribute to the much needed shift toward a more livable urban ecosystem. 
Regardless of how the knowledge we generated together is used, the chance for multiple publics across Troy to encounter an eruption of plant biodiversity emerging from a seemingly immutable lawn is an end in itself. As we move ahead with the project, we hope that a moment of cognitive dissonance or surprise accompanies this encounter, perhaps leaving room for fresh forms of ecological consciousness to take root. Reawakening these weedy beings from the soil seed bank is one step toward sharing the idea that spontaneous urban plants can be partners in ecosystem restoration and the pursuit of environmental justice. Critically engaged, ecosocial art that takes the form of a public experiment is one of many practices that is well suited to pursuing these ends. It provides a forum for bringing together contradictory and complementary ideas and practices across disciplines, and a framework for testing and enacting new possibilities for multispecies thriving. In the case of Lawn Lab, these tensions and realizations come to the surface gradually, across a growing season, at the pace of seeds unfurling into plants. 


\section{REFERENCES}

Albrecht, Harald, Elisabeth Eder, Thomas Langbehn, and Clara Tschiersch. 2011. "The Soil Seed Bank and Its Relationship to the Established Vegetation in Urban Wastelands." Landscape and Urban Planning 100 (1-2): 87-97. https://doi.org/10.1016/j.landurbplan.2010.11.011.

Allaby, Michael. 2015a. "Pioneer Plant." In A Dictionary of Ecology. Oxford University Press. http://www.oxfordreference.com/view/10.1093/acref/9780191793158.001.0001/ acref-9780191793158-e-4314.

- - . 2015b. Succession. In A Dictionary of Ecology. . Oxford University Press. http://www.oxfordreference.com/view/10.1093/acref/9780191793158.001.0001/ acref-9780191793158-e-5458.

Allen, Will, Diana Balmori, Rosalind Creasy, Fritz Haeg, Michael Pollan, Eric Sanderson, and Lesley Stern. 2010. Edible Estates: Attack on the Front Lawn. 2nd Revised. A Project by Fritz Haeg. New York: Metropolis Books.

Anderson, Eric. 2018. "Housing Rehabilitation Group Marks 50 Years.” Times Union, October 6, 2018. 2018. https://www.timesunion.com/business/article/Housing-rehabilitation-groupmarks-50-years-13287071.php.

Ashrafzadeh, Seyedardalan, Niklas J. Lehto, Gareth Oddy, Ron G. McLaren, Lingfen Kang, Nicholas M. Dickinson, Johannes Welsch, and Brett H. Robinson. 2018. "Heavy Metals in Suburban Gardens and the Implications of Land-Use Change Following a Major Earthquake." Applied Geochemistry, SI: Trace Elements in Soils 88 (January): 10-16. https://doi.org/10.1016/ j.apgeochem.2017.04.009.

Branas, Charles C., Rose A. Cheney, John M. MacDonald, Vicky W. Tam, Tara D. Jackson, and Thomas R. Ten Have. 2011. "A Difference-in-Differences Analysis of Health, Safety, and Greening Vacant Urban Space.” American Journal of Epidemiology 174 (11): 1296-1306. https://doi.org/ $\underline{10.1093 / \mathrm{aje} / \mathrm{kwr} 273}$.

Brown, Adrienne Maree. 2017. Emergent Strategy: Shaping Change, Changing Worlds. Reprint edition. Chico, CA: AK Press.

Capital District Regional Planning Commission. 2019. “CDRPC Census Mapper Version 1.1.0.” August 12, 2019. http://maps.cdrpc.org/.

Castañeda-Álvarez, Nora P., Colin K. Khoury, Harold A. Achicanoy, Vivian Bernau, Hannes Dempewolf, Ruth J. Eastwood, Luigi Guarino, et al. 2016. "Global Conservation Priorities for Crop Wild Relatives.” Nature Plants 2 (4): 16022. https://doi.org/10.1038/nplants.2016.22.

Cavicchi, Julia, Durasia Anderson, and The Sanctuary for Independent Media. 2018. "Interactive Map: Environmental Justice at Census Tract 404. The Sanctuary for Independent Media (Blog) August 22, 2018.” 2018. https://www.mediasanctuary.org/art-galleries/naturelab-gallery/ interactive-map-environmental-justice-at-census-tract-404/.

City of Troy. n.d. City of Troy, NY: Weeds. Accessed December 17, 2019. https://ecode360.com/ $\underline{11132250 .}$.

Crenshaw, Kimberlé. 1989. "Demarginalizing the Intersection of Race and Sex: A Black Feminist Critique of Antidiscrimination Doctrine, Feminist Theory and Antiracist Politics." The University of Chicago Legal Forum 140: 139-67.

Crist, Eileen. 2019. "The Destruction of Life and the Human Supremacy Complex." In Abundant Earth: Toward an Ecological Civilization. University of Chicago Press. https://doi.org/10.7208/ chicago/9780226596945.001.0001/upso-9780226596778. 
Davis, Brian. 2016. "CSOs and Landscape as Infrastructure in Troy, NY."

https://wri.cals.cornell.edu/sites/wri.cals.cornell.edu/files/shared/documents/

2015_Davis_Final.pdf.

Davis, Heather, and Zoe Todd. 2017. "On the Importance of a Date, or, Decolonizing the Anthropocene.” ACME: An International Journal for Critical Geographies 16 (4): 761-80.

Del Tredici, Peter. 2014. “The Flora of the Future.” Places Journal, no. 2014 (April).

https://doi.org/10.22269/140417.

Del Tredici, Peter, and Steward T.A. Pickett. 2010. Wild Urban Plants of the Northeast: A Field Guide. 1st ed. Ithaca: Comstock Publishing Associates.

Ellis, Rebecca. 2017. "Lawns, Class, and Colonialism.” Permaculture for the People (Blog) October 26, 2017.” 2017. https://permacultureforthepeople.org/2017/10/25/lawns-class-and-colonialismpart-one/.

Fisher, Marc, and Joel Achenbach. 2019. "Boundless Racism, Zero Remorse: A Manifesto of Hate and 49 Dead in New Zealand." Washington Post, March 15, 2019.

https://www.washingtonpost.com/national/boundless-racism-zero-remorse-a-manifesto-of-hateand-49-dead-in-new-zealand/2019/03/15/3d407c64-4738-11e9-90f0-0ccfeec87a61_story.html.

Fitzgerald, Cathy. 2019. "The Hollywood Forest Story-Eco-Social Art Practice for the Symbiocene.” Minding Nature 12 (3): 53-58.

Geniusz, Mary Siisip. 2015. Plants Have So Much to Give Us, All We Have to Do Is Ask: Anishinaabe Botanical Teachings. Edited by Wendy Makoons Geniusz. 1st ed. Minneapolis: University of Minnesota Press.

Gu, Chuanhui, John II Crane, George Hornberger, and Amanda Carrico. 2015. "The Effects of Household Management Practices on the Global Warming Potential of Urban Lawns." Journal of Environmental Management 151 (March): 233-42. https://doi.org/10.1016/ j.jenvman.2015.01.008.

Guha, Ramachandra. 1989. "Radical American Environmentalism and Wilderness Preservation: A Third World Critique.” Environmental Ethics 11 (1): 71-83. https://doi.org/10.5840/ enviroethics 198911123.

Haraway, Donna. 2003. The Companion Species Manifesto. Chicago: University of Chicago Press. https://www.press.uchicago.edu/ucp/books/book/distributed/C/bo3645022.html.

_-_. 2015. "Anthropocene, Capitalocene, Plantationocene, Chthulucene: Making Kin." Environmental Humanities 6: 159-65.

Heise, Ursula K. 2008. Sense of Place and Sense of Planet: The Environmental Imagination of the Global. New York: Oxford University Press. https://doi.org/10.1093/acprof:oso/ $\underline{9780195335637.001 .0001 .}$

Hobbs, Richard J., Eric S. Higgs, and Carol Hall. 2013. Novel Ecosystems: Intervening in the New Ecological World Order. West Sussex, UK: John Wiley \& Sons, Incorporated. http://ebookcentral.proquest.com/lib/rpi/detail.action?docID=1120678.

Ignatieva, Maria, Karin Ahrné, Jörgen Wissman, Tuula Eriksson, Pernilla Tidåker, Marcus Hedblom, Thomas Kätterer, et al. 2015. "Lawn as a Cultural and Ecological Phenomenon: A Conceptual Framework for Transdisciplinary Research.” Urban Forestry $\Xi^{\circ}$ Urban Greening 14 (2): 383-87. https://doi.org/10.1016/j.ufug.2015.04.003.

Irons, Ellie. 2017. "Weedy Resistance: Multispecies Tactics for Contesting 'The Age of Man.” Inhabiting the Anthropocene (Blog).” May 3, 2017. https://inhabitingtheanthropocene.com/ 2017/05/03/weedy-resistance-multispecies-tactics-for-contesting-the-age-of-man/. 
Kalisz, Susan. 1990. "Soil Seed Banks.” Edited by Mary A. Leck, V. Thomas Parker, and Robert L. Simpson. Ecology 71 (3): 1226-27. https://doi.org/10.2307/1937400.

Kimmerer, Robin Wall. 2015. Braiding Sweetgrass: Indigenous Wisdom, Scientific Knowledge and the Teachings of Plants. Milkweed Editions.

Kirksey, S. Eben, and Stefan Helmreich. 2010. "The Emergence of Multispecies Ethnography.” Cultural Anthropology 25 (4): 545-76. https://doi.org/10.1111/j.1548-1360.2010.01069.x.

Kremer, Peleg, Zoé A. Hamstead, and Timon McPhearson. 2013. "A Social-Ecological Assessment of Vacant Lots in New York City." Landscape and Urban Planning 120 (Supplement C), December, 218-33. https://doi.org/10.1016/j.landurbplan.2013.05.003.

Krzeminski, Jessica. 2019. "Whose Utopia? American Ecofascism Since the 1880s.” Edge Effects, October 10, 2019. https://edgeeffects.net/ecofascism/.

Martin, Edwin nd. n.d. "Our History: Many Trails." Stockbridge-Munsee Community Band of Mohican Indians.” Accessed June 15, 2020. https://www.mohican.com/?url=our-history.

Meyer, Robinson. 2019. “This Land Is the Only Land There Is.” The Atlantic, August 8, 2019. https://www.theatlantic.com/science/archive/2019/08/how-think-about-dire-new-ipcc-climatereport $/ 595705 /$.

Moore, Jason W. 2015. Capitalism in the Web of Life: Ecology and the Accumulation of Capital. New York: Verso.

Nixon, Rob. 2011. Slow Violence and the Environmentalism of the Poor. Cambridge, Mass: Harvard University Press. https://doi.org/10.4159/harvard.9780674061194.

Orion, Tao, and David Holmgren. 2015. Beyond the War on Invasive Species: A Permaculture Approach to Ecosystem Restoration. White River Junction, Vermont: Chelsea Green Publishing.

Out of the Woods. 2018. “The Dangers of Reactionary Ecology.” Libcom.Org (Blog). 2018. http://libcom.org/blog/dangers-reactionary-ecology-30062014.

Phillips, Daniel. 2017. "Ecologies of Elsewhere: Giving Urban Weeds a 'Third Glance'.” The Nature of Cities (blog). September 6, 2017. https://www.thenatureofcities.com/2017/09/06/ecologieselsewhere-giving-urban-weeds-third-glance/.

Plumwood, Val. 1994. Feminism and the Mastery of Nature. Routledge.

Pollan, Michael. 2003. Second Nature: A Gardener's Education. Reprint edition. New York: Grove Press.

Robbins, Paul. 2007. Lawn People: How Grasses, Weeds, and Chemicals Make Us Who We Are. Annotated edition. Philadelphia: Temple University Press.

Robbins, Paul, and Julie Sharp. 2006. "Turfgross Subjects: The Political Economy of Urban Monoculture." In In the Nature of Cities: Urban Political Ecology and the Politics of Urban Metabolism, edited by Nik Heynen, Maria Kaika, and Erik Swyngedouw, 1st edition. New York: Routledge.

Rupprecht, Christoph D. 2017. Informal Urban Green Space as Anti-Gentrification Strategy? In Just Green Enough. Edited by Winifred Curran and Trina Hamilton. 1st edition, 209-26. New York: Routledge.

Shiva, Vandana. 2006. "Diversity Is the Key to Halting Climate Chaos." The Guardian, June 6, 2006, sec. Society, . https://www.theguardian.com/society/2006/jun/07/ guardiansocietysupplement1. 
SSE. n.d. "Seed Savers Exchange Heirloom Seeds.” Accessed December 14, 2019.

https://www.seedsavers.org/.

Stevenson, Angus, ed. 2010. "Ruderal." In Oxford Dictionary of English. Oxford University Press. https://doi.org/10.1093/acref/9780199571123.001.0001/acref-9780199571123.

Stoetzer, Bettina. 2018. "Ruderal Ecologies: Rethinking Nature, Migration, and the Urban Landscape in Berlin." Cultural Anthropology 33 (2): 295-323. https://doi.org/10.14506/ca33.2.09.

Taylor, Affrica, and Veronica Pacini-Ketchabaw. 2015. "Learning with Children, Ants, and Worms in the Anthropocene: Towards a Common World Pedagogy of Multispecies Vulnerability." Pedagogy, Culture E' Society 23 (4): 507-29. https://doi.org/10.1080/14681366.2015.1039050.

Telewski, Frank W., and Jan A. D. Zeevaart. 2002. "The 120-Yr Period for Dr. Beal's Seed Viability Experiment.” American Journal of Botany 89 (8): 1285-88. https://doi.org/10.3732/ajb.89.8.1285.

Third Space Galway. 2019. "Sights of Regeneration.” 2019. http://thirdspacegalway.ie/cocreatingthe-ecopolis/.

Todd, Zoe. 2016. “An Indigenous Feminist's Take On The Ontological Turn: 'Ontology' Is Just Another Word For Colonialism.” Journal of Historical Sociology 29 (1): 4-22. https://doi.org/ $\underline{10.1111 / \text { johs. } 12124 .}$.

Tsing, Anna Lowenhaupt. 2011. "A History of Weediness." In Friction: An Ethnography of Global Connection, 171-202. Princeton: Princeton University Press.

United States Environmental Protection Agency. 2019. "Hudson River Cleanup I Hudson River PCBs Superfund Site.” 2019. https://www3.epa.gov/hudson/cleanup.html.

WELRP. n.d. "Indigenous Seed Library." Accessed December 14, 2019. https://www.welrp.org/ about-welrp/indigenous-seed-library/.

Westengen, Ola T., Simon Jeppson, and Luigi Guarino. 2013. "Global Ex-Situ Crop Diversity Conservation and the Svalbard Global Seed Vault: Assessing the Current Status.” Edited by Wengui Yan. PLOS ONE 8 (5): e64146. https://doi.org/10.1371/journal.pone.0064146.

Whyte, Kyle Powys. n.d. “Indigenous Peoples and Climate Justice.” Accessed July 30, 2019. https://www.youtube.com/watch?v=7YPvsOCUhI8. 